\title{
Quantification of Powder Spreading Process for Metal Additive Manufacturing
}

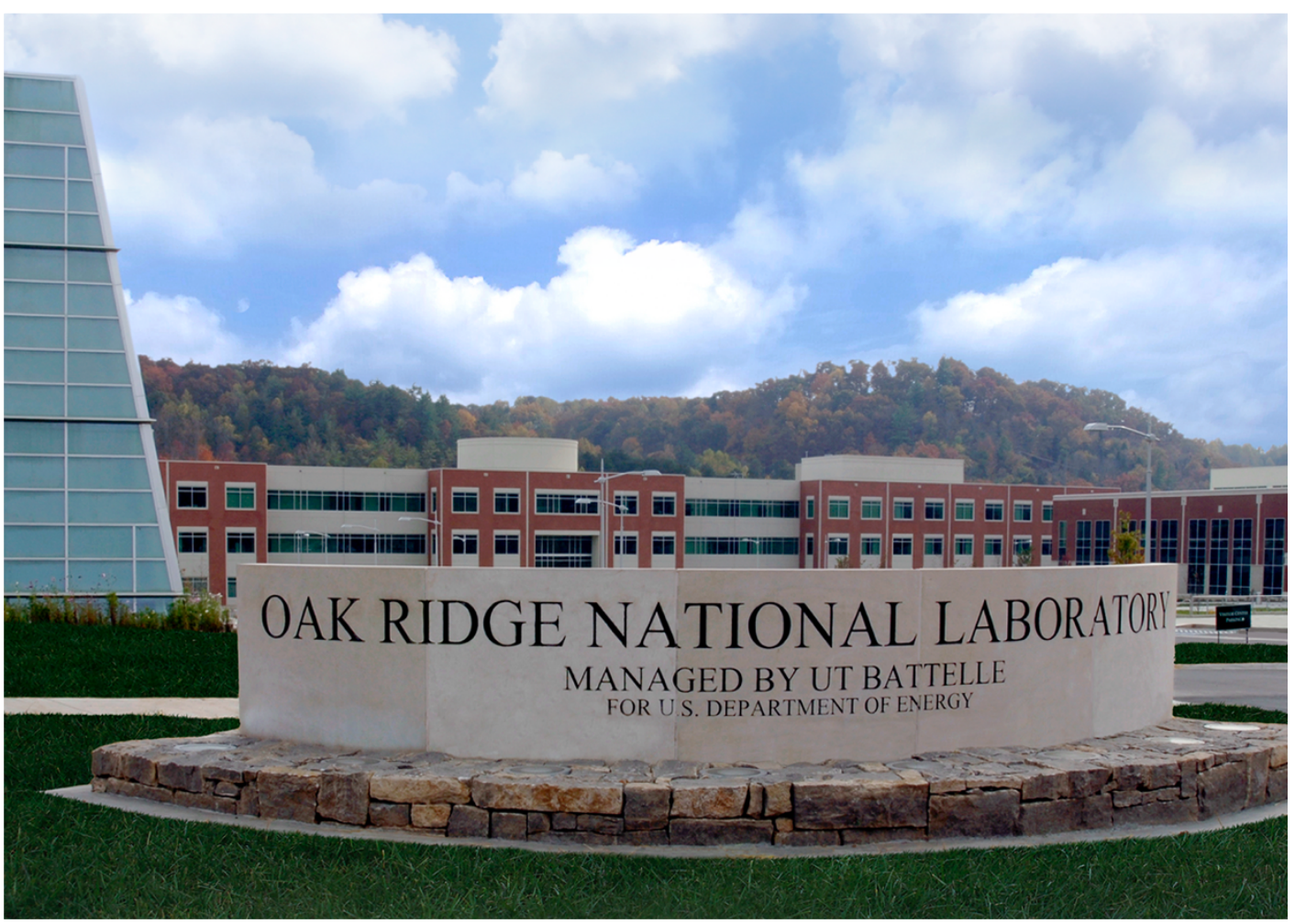

CRADA FINAL REPORT NFE-17-06812

Approved for Public Release. Distribution is Unlimited.
Yousub Lee

Srdjan Simunovic

A. Kate Gurnon

October 10, 2019 


\section{DOCUMENT AVAILABILITY}

Reports produced after January 1, 1996, are generally available free via US Department of Energy (DOE) SciTech Connect.

\section{Website http://www.osti.gov/scitech/}

Reports produced before January 1, 1996, may be purchased by members of the public from the following source:

National Technical Information Service

5285 Port Royal Road

Springfield, VA 22161

Telephone 703-605-6000 (1-800-553-6847)

TDD 703-487-4639

Fax 703-605-6900

E-mail info@ntis.gov

Website http://www.ntis.gov/help/ordermethods.aspx

Reports are available to DOE employees, DOE contractors, Energy Technology Data Exchange representatives, and International Nuclear Information System representatives from the following source:

Office of Scientific and Technical Information

PO Box 62

Oak Ridge, TN 37831

Telephone 865-576-8401

Fax 865-576-5728

E-mail reports@osti.gov

Website http://www.osti.gov/contact.html 
This report was prepared as an account of work sponsored by an agency of the United States Government. Neither the United States Government nor any agency thereof, nor any of their employees, makes any warranty, express or implied, or assumes any legal liability or responsibility for the accuracy, completeness, or usefulness of any information, apparatus, product, or process disclosed, or represents that its use would not infringe privately owned rights. Reference herein to any specific commercial product, process, or service by trade name, trademark, manufacturer, or otherwise, does not necessarily constitute or imply its endorsement, recommendation, or favoring by the United States Government or any agency thereof. The views and opinions of authors expressed herein do not necessarily state or reflect those of the United States Government or any agency thereof. 


\section{Computational Sciences and Engineering Division} Advanced Manufacturing Office

\section{Quantification of Powder Spreading Process for Metal Additive Manufacturing}

Yousub Lee Srdjan Simunovic
A. Kate Gurnon

Date Published: September 26, 2019

Prepared by

OAK RIDGE NATIONAL LABORATORY

Oak Ridge, Tennessee 37831-6283

managed by

UT-BATTELLE, LLC

for the

US DEPARTMENT OF ENERGY

under contract DE-AC05-00OR22725

Approved for Public Release 


\section{CONTENTS}

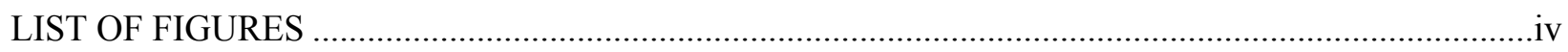

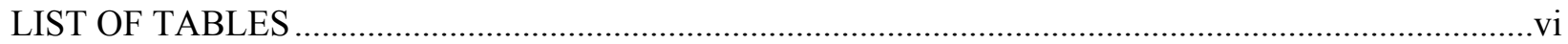

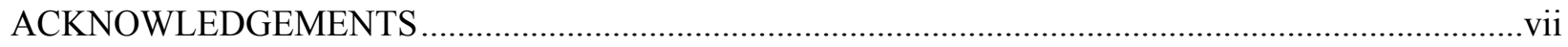

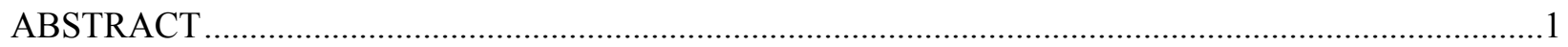

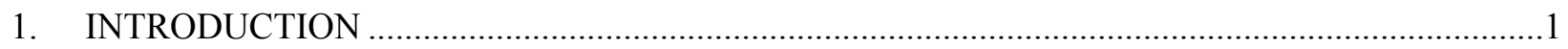

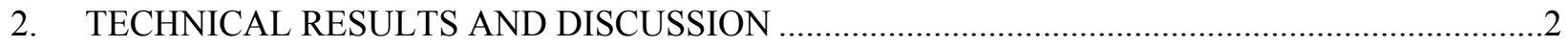

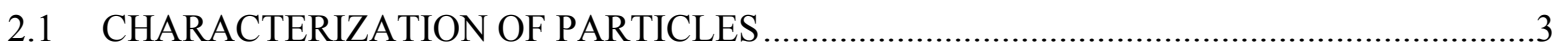

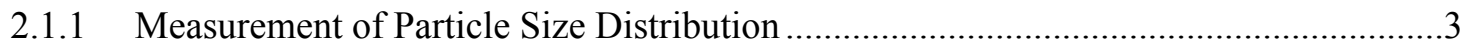

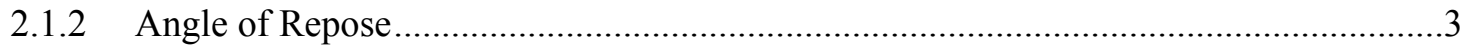

2.1.3 Powder Spreading System .................................................................................

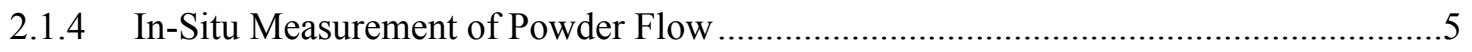

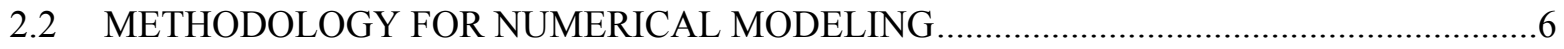

2.2.1 Discrete Element Method for Powder Spreading ......................................................6

2.2.2 Calculation of Fabric Tensor ...........................................................................

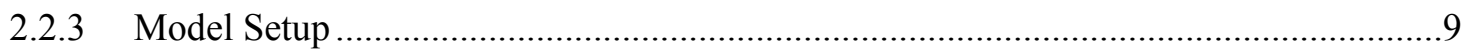

2.2.4 Workflow for simulations of spreading of multiple layers ...........................................10

2.3 EFFECT OF PARTICLE SPREADING DYNAMICS ON POWDER BED QUALITY .........12

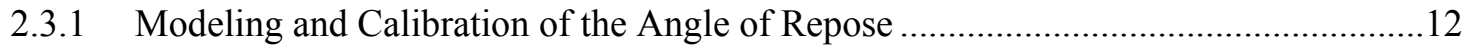

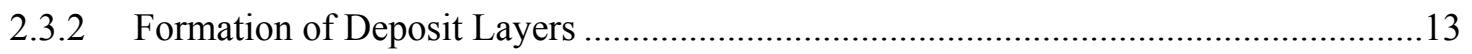

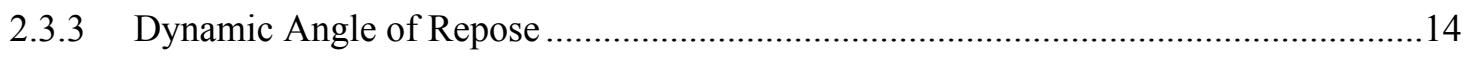

2.3.4 Influence of Rake Velocity on Powder Bed Quality...................................................16

2.4 QUANTIFICATION OF POWDER SPREADING PROCESS ...........................................19

2.4.1 Scalar methods: Packing Density, Coordination Number, Particle Size

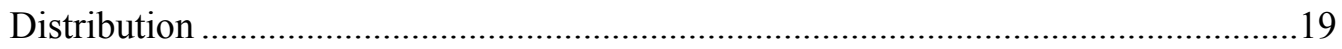

2.4.2 Tensorial Method: Orientation of Inter-Particle Contacts ..........................................22

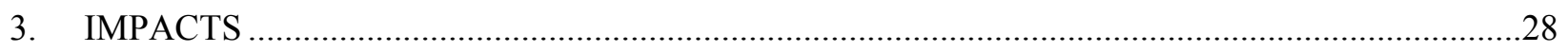

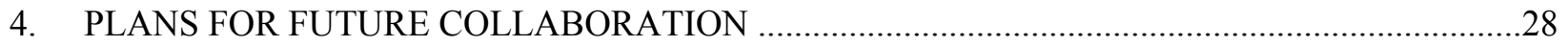

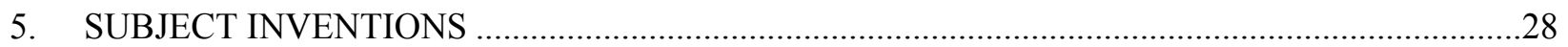

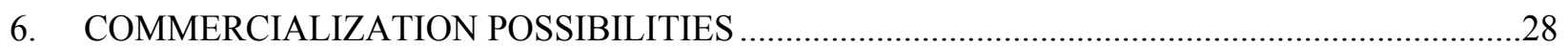

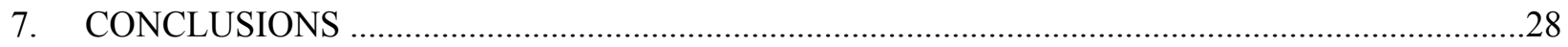

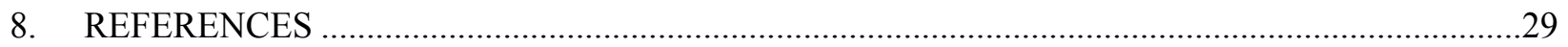




\section{LIST OF FIGURES}

Figure 1. (a) Measured and converted particle size distribution and (b) particles in DEM simulation

Figure 2. Experimental setup for angle of repose (AOR) (a) Empty box, (b) Half-filled particles before the experiment performed, and (c) The slit is sliced out and the particles form the angle. The measured value of AOR is $33.0^{\circ}$. 3

Figure 3. Powder spreading set-ups.

Figure 4. (a) calibration at the focus plane at the center along the recoater blade, (b) example of the dynamic angle of repose, $\theta$, measured during the spreading event. 5

Figure 5. Illustration of spheres in contact showing contact normal vector.

Figure 6. Simulation setup for AOR prediction, 105,000 particles are filled with half of the box and fall as the bottom plate slides out. .8

Figure 7. Computation domain for powder spreading simulation. .9

Figure 8. Workflow to model the layer deposition process. The initial particle stacks in (a) are inserted at every beginning of the deposition, (b) and (d) which method significantly reduces the total computation time. The spreading steps are shown in (c) for the first and (e) for the second layer.

Figure 9. Effect of static friction and rolling coefficient on AOR. Both coefficients showed little influence on the change of AOR.

Figure 10. The predicted AOR with particle cohesion energy (a) 3.0e+7, (b) $3.5 \mathrm{e}+7$ and (c) $3.6 \mathrm{e}+7$ that shows the best match with the measured value of $33.0^{\circ}$.

Figure 11. Validation of the predicted powder bed height. The bed height matches well with the experiment. The predicted bed height matches with the measured height (in Table 1) within 1\% error range.

Figure 12. Comparison of dynamic AOR with experiment, (a) Evolution of dynamic AOR with time, (b)-(d) Characteristic geometry of powder pile compared with experimental images.

Figure 13. Evolution of dynamic AOR with rake velocity. High velocity increases the dynamic AOR and the gradient of angle variation.

Figure 14. Variation of (a) packing density and (b) surface roughness with rake velocity...........15

Figure 15. Particle segregation on the top surface of the powder stack front .16

Figure 16. Comparison of the measured PSD with the predicted PSD at before spreading and after spreading.

Figure 17. A shift of PSD as a function of rake velocity. Higher rake velocity drives PSD shift to finer region.

Figure 18. Evolution of average coordination number because of interaction with recoater system. Roller compresses the particles and increases interparticle contact at the beginning of the spreading process. 
Figure 19. Variation of overall coordination number $(\mathrm{CN})$ in the powder bed at different recoater velocities. Change of recoater geometry shows little effect on $\mathrm{CN}$...

Figure 20. Correlation of overall packing density with overall coordination number $(\mathrm{CN})$ as a function of rake velocity.

Figure 21. Local variation of packing density (PD) and coordination number $(\mathrm{CN})$ at rake velocity of $2.54 \mathrm{~cm} / \mathrm{s}$. Interaction of particles with recoater system leads to change of powder bed configuration

Figure 22. Fabric tensor plot using rose diagram with (a) second and (b) forth-order tensors. The difference between the second and fourth-order fabric tensors shows that the fourth order provides an additional detailed description of interparticle contacts in the powder bed. .20

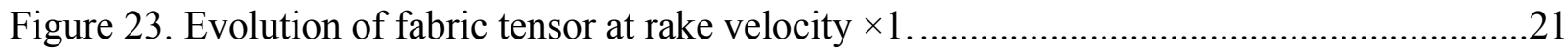

Figure 24. Evolution of fabric tensor at rake velocity $\times 5$.

Figure 25. Initial boundary condition for heat transfer simulation. Heat source with $1300{ }^{\circ} \mathrm{C}$ and $500 \mu \mathrm{m}$ diameter was applied to heat up the powder bed.

Figure 26. Temperature distribution at the end of simulation at (a) start, (b) center and (c) end region in the powder bed at $\mathrm{x} 1$ rake velocity.

Figure 27. Roundness plot for heat conduction at the (a) start, (b) center and (b) end region in the powder bed. Smaller roundness indicates that non-uniform heat conduction occurs in the powder bed.

Figure 28. Representation of spherical harmonic. 


\section{LIST OF TABLES}

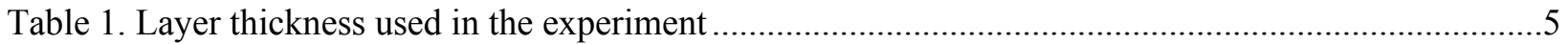




\section{ACKNOWLEDGEMENTS}

This research was supported by the High-Performance Computing for Manufacturing Project Program (HPC4Mfg), managed by the U.S. Department of Energy Advanced Manufacturing Office within the Energy Efficiency and Renewable Energy Office. This research used resources of the Compute and Data Environment for Science (CADES) at the Oak Ridge National Laboratory (ORNL), which is supported by the Office of Science of the U.S. Department of Energy under Contract No. DE-AC05-00OR22725. 


\begin{abstract}
In powder bed additive manufacturing (AM), the powder spreading process can lead to inhomogeneity in layer height, porosity level, and particle size distribution. Hence, creating homogeneous layers is the first task for optimal printing. The conventional assessment methods for powder quality are limited to a measurement of powder morphology, flowability, particle size distribution, surface roughness, and packing density. However, those techniques may not be the most appropriate to quantify the powder bed characteristics since it is not able to capture local particle configuration and does not provide any vectoral information (e.g., arrangement of contacts between particles during spreading). In this project, we: 1) developed a powder spreading model using discrete element method (DEM) for multiple-layered process, 2) experimentally measure powder spreading dynamics including static angle of repose (AOR) and dynamic AOR in order to calibrate and subsequently validate the model, and 3) investigated the effect of particle spreading process parameters on spatial powder bed structure and quality using scalar (e.g., porosity, surface roughness, coordination number, and particle size distribution) and tensorial (e.g., directionality of inter-particle contacts) methods for a comprehensive quantification of powder bed.
\end{abstract}

\title{
1. INTRODUCTION
}

Additive manufacturing (AM) encompasses a suite of technologies that make three-dimensional (3D) objects incrementally, layer by layer. Two key steps in that 3D construction are: (i) powder spreading wherein a pile of powder is pushed over an existing surface (build plate or previous powder layer) to spread a thin layer of powder, and (ii) powder fusion or binding wherein powder particles are selectively fused (via application of a laser or electron beam) or bound (via deposition of fluidic binders, e.g., in inkjet printing) together to shape a solid, cohesive, 3D object.

The powder spreading process in powder-bed based AM often leads to layers with varying heights and areas of high porosity (two culprits for defective parts). A bulk of the research in powder-bed based AM is mostly concerned with the second step, namely powder fusion or binding step, assuming regularly packed particles and thereby an ideal powder spreading. However, the powder spreading is far from ideal and often the main culprit for two powder layer defects: (a) varying heights (or high roughness), and (b) high porosity. The lack of fundamental understanding of powder spreading process has led to: 1) a very limited choice of powder material, 2) part defects caused by non-uniform layers and porosity, and 3) a highly empirical process tuning that is time- and cost-inhibitive. The outcome of the latter is often a solution that features default spreading speeds and slow printing rates.

To address this identified AM technology gap, we have developed experimental techniques and computational models for powder spreading and the resulting particle configurations. The GE global research center (GRC) team used its expertise in powder mechanics and tribology as well as metal additive processes to develop experimental technologies for powder and process characterization. The ORNL team developed the computational models for powder spreading using High-Performance Computing (HPC) and computational modeling tools tuned to the experimental results performed by the GE GRC. The computational model is based on the Discrete Element Method (DEM) that represents powder as a collection of interacting discrete particles. The collide, slide, and clump are based on the interaction models which must be derived from the experiments. The number of particles required for modeling powder spreading is large and requires correspondingly large computational resources. For 
three-dimensional problems, these are considered in this study, the computational demands quickly scale out of realm of computational feasibility in the industrial setting and necessarily have to be constrained by the engineering insight, and domain size. The ORNL's HPC capabilities enable us to minimize those limitations and provide predictive computational framework that can be scaled and transferred into industrial research and production settings.

In the following, we describe the development of the HPC computational framework for modeling powder spreading supported by the experimental techniques for process and powder characterization. Rheological properties of commercially available powder systems were measured to characterize the energy and resistance required to spread powders. A computational modeling framework for the powder spreading process was developed and experimental data was used to tune the particle interaction models and other process variables. Powder spreading under various conditions was then simulated using the developed framework and the HPC resources. The simulations of spreading of powder across multiple layers show good correlation to experiments. Computational results provide spatial distribution of powder size distribution, segregation, powder configuration, anisotropy, transport properties, as a function of process parameters. The results meet the goals of HPC4MFG program by using the HPC as an enabling technology to address an industry-wide problem by developing a model-based predictive framework for powder spreading process. The results of this project will accelerate transformational technological advances in metal AM space. Developed computational framework and the supporting experimental technology support optimization of powder spreading process, reduction of testing cycles, shortening of time to market, and reducing waste and rejected parts.

\section{TECHNICAL RESULTS AND DISCUSSION}

In this section, we introduce key results generated from the experiment and simulation performed by GE and ORNL and discuss the significance of the findings. The outline is as follows. Section 1 presents the experimental methodologies how the powder properties and flow behavior were determined using laser light diffraction particle size analyzer, angle of repose method, powder spreading system, and in-situ measurement tool. Section 2 shows the numerical methodologies used to establish multi-layer DEM simulation framework. Section 3 validates the computational model in comparison with the measured data and extends to capture characteristic features of powder layer under the various combination of spreading conditions. Section 4 shows unique approaches for full quantification of powder bed. The potential impact of inhomogeneous powder bed quality is demonstrated using heat transfer model.

\subsection{CHARACTERIZATION OF PARTICLES}

\subsubsection{Measurement of Particle Size Distribution}

The size and distribution of Co-Cr particles were measured using a Microtrac S3500 laser light diffraction particle size analyzer. The powder lots particle size range is between $25 \mu \mathrm{m}$ to $105 \mu \mathrm{m}$. The measured $\mathrm{D}_{10}, \mathrm{D}_{50}$ and $\mathrm{D}_{90}$ are $29.84 \mu \mathrm{m}, 52.08 \mu \mathrm{m}$ and $86.11 \mu \mathrm{m}$, respectively. The measured particle size distribution (PSD) values were converted into LIGGGHTS simulation [1] based on the $\mathrm{D}_{10} \sim \mathrm{D}_{95}$ 
values. Figure 1 shows (a) the measured and converted particle size, and distribution and (b) particles in the DEM simulation.

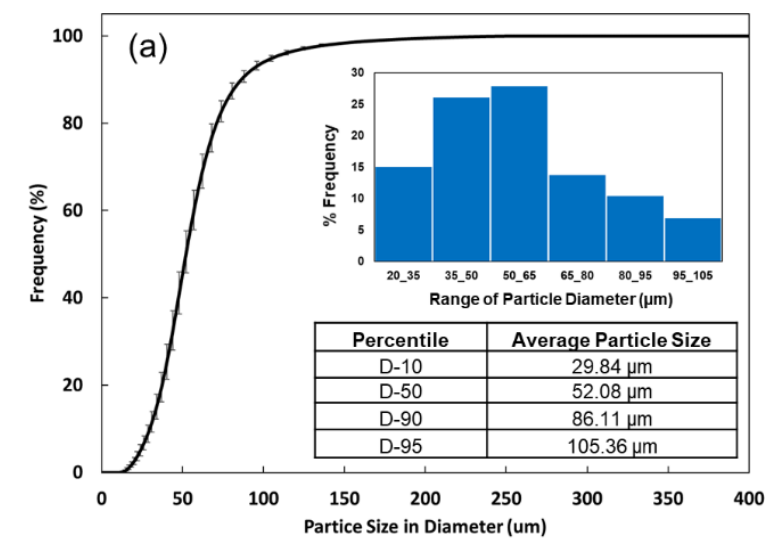

(b) Rad.

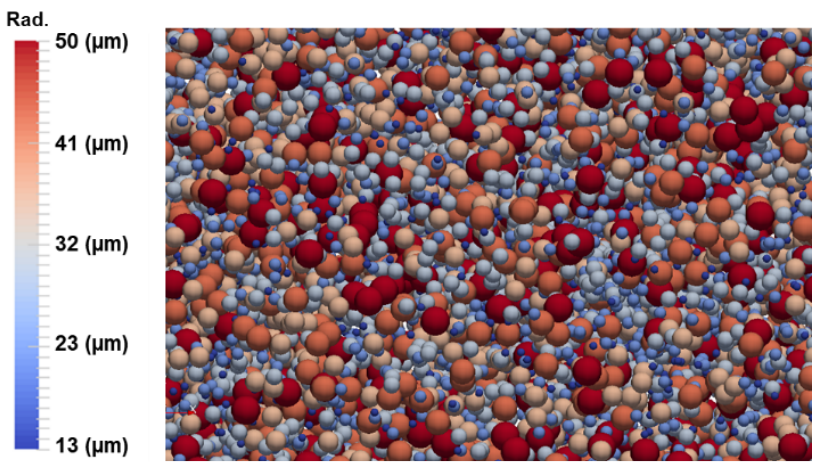

Figure 1. (a) Measured and converted particle size distribution and (b) particles in DEM simulation.

\subsubsection{Angle of Repose}

The experimental setup for angle of repose measurements (AOR) is presented in Figure 3. The dimension of the box in Figure 2(a) is $40 \mathrm{~mm}(\mathrm{~L}) \times 30 \mathrm{~mm}(\mathrm{~W}) \times 35 \mathrm{~mm}(\mathrm{H})$. Initially, the powder is scooped with a spatula and fills about $50 \%$ of the box, Figure 3(b). Once the powder is loaded, the bottom plate of the measurement system slides to the left such that powder falls into the bottom reservoir. As a result, the remaining particles on the bottom plate in the Figure 3(c) creates the pile-up. The disk behind the powder is adjusted until the visual lines align with the angle of the powder pile, thus measuring the static angle of repose. The experimental result for this lot of CoCr powder is a measured angle of repose of $33^{\circ}$.

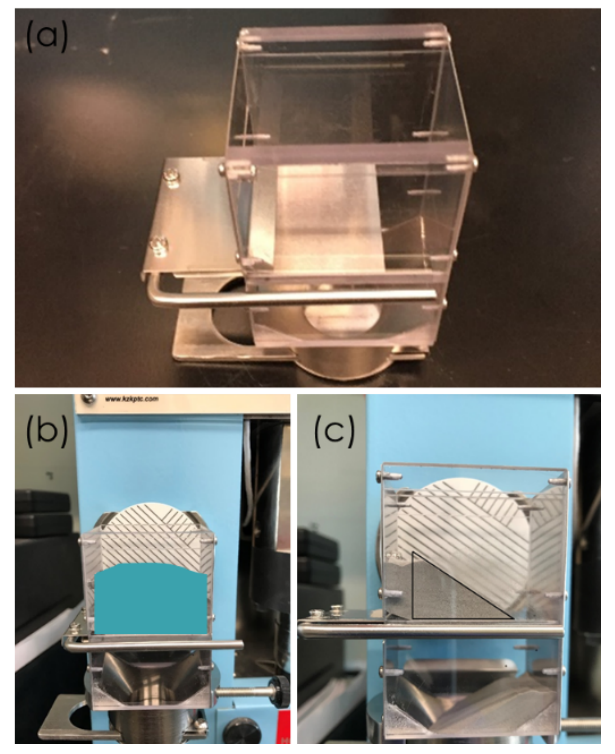

Figure 2. Experimental setup for angle of repose (AOR) (a) Empty box, (b) Half-filled particles before the experiment performed, and (c) The slit is sliced out and the particles form the angle. The measured value of AOR is $33.0^{\circ}$. 


\subsubsection{Powder Spreading System}

A powder bed test rig was designed and built to evaluate powder spreading onto a bed. To do this, we opted to utilize a moving stage and a stationary blade such that the dynamic angle of repose can be measured using a stationary camera perpendicular to the stage and aligned with the recoater blade, in Figure 3. The recoater blade is a Concept Laser hard recoater fixed to a stationary stand. Powder is dropped onto the test platform from above the plate and then spread at a fixed speed $(2.54 \mathrm{~cm} / \mathrm{s}, 5.08 \mathrm{~cm} / \mathrm{s}$ or $12.7 \mathrm{~cm} / \mathrm{s}$ ) dictated by the speed of the moving stage. The blade can be adjusted to accommodate powder layer thicknesses in increments of $102 \mu \mathrm{m}$ to $127 \mu \mathrm{m}$ after an initial bed of $\sim 1 \mathrm{~mm}$ is placed onto the stage.

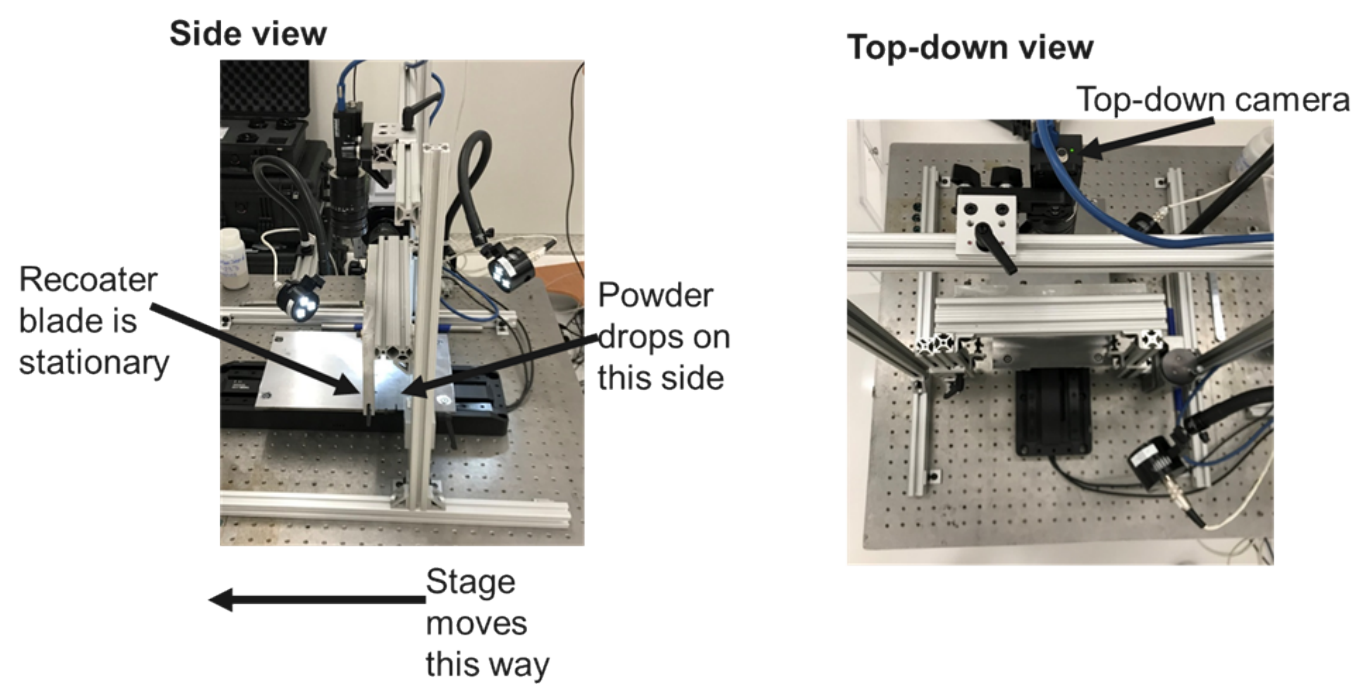

Figure 3. Powder spreading set-ups.

Table 1 presents the different layer thicknesses achieved for the $2.54 \mathrm{~cm} / \mathrm{s}$ recoating experiments. Initially, the powder bed is charged with $\sim 1 \mathrm{~mm}$ of powder to create the powder bed. Then the bed recoater coats a $\sim 100 \mu \mathrm{m}$ layer powder layer while the camera is used to capture the dynamic angle of repose resulting in the interaction between the powder being deposited onto the bed with the existing 1 mm powder bed on the moving stage.

Table 1. Layer thickness used in the experiment

\begin{tabular}{|c|c|c|}
\hline Layer \# & Layer thickness & Total bed height \\
\hline 1 & $508 \mu \mathrm{m}$ & $508 \mu \mathrm{m}$ \\
\hline 2 & $508 \mu \mathrm{m}$ & $1016 \mu \mathrm{m}$ \\
\hline 3 & $102 \mu \mathrm{m}$ & $1118 \mu \mathrm{m}$ \\
\hline 4 & $127 \mu \mathrm{m}$ & $1245 \mu \mathrm{m}$ \\
\hline
\end{tabular}




\subsubsection{In-Situ Measurement of Powder Flow}

During each powder spreading experiment the images were captured using a Point Grey GS3-U350S5M-C camera. An initial calibration image was used to determine the length scale on the center plane of the recoater blade, Figure 4(a). The focus is maintained on this plane throughout the experiments.

Image post-processing was performed to determine the dynamic angle of repose the powder makes with the existing powder bed, $\theta$, for each image captured during the experiment, Figure 4(b). Image analysis was done using Clemex, Inc. vision image analysis software version 8 . A routine was written that sequentially opened the images beginning with the start of spreading each layer. Each image in the selected folder would be enhanced for sharpness to brighten the image and make it easier to discern the angle of the powder. The angle of the powder was observed and an angle tool was used to draw a line which aligned with the apparent angle of the loose powder and automatically quantified.

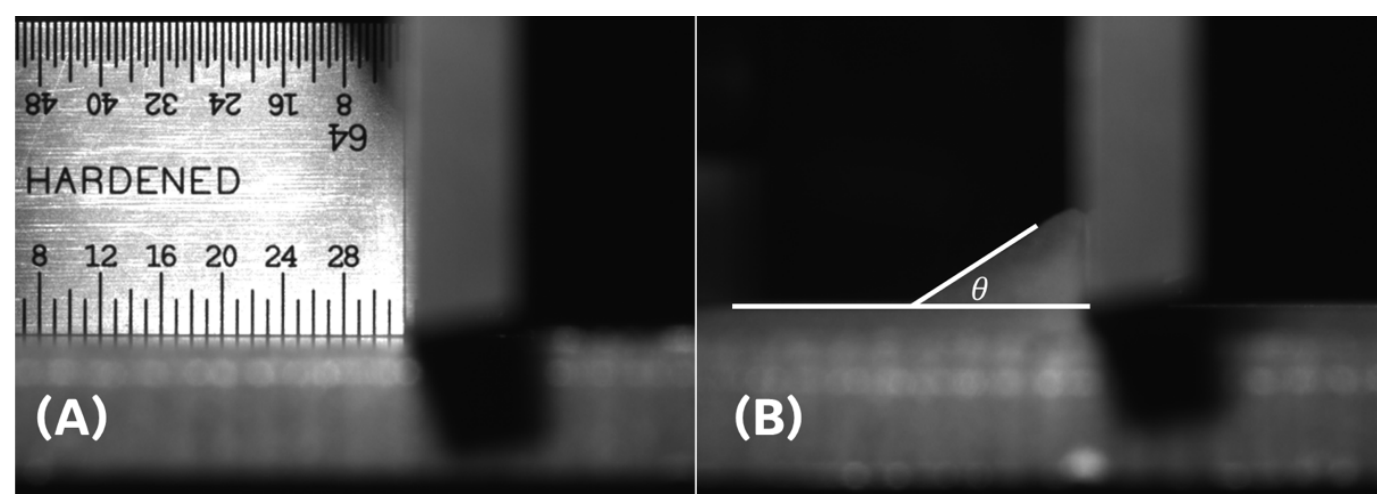

Figure 4. (a) calibration at the focus plane at the center along the recoater blade, (b) example of the dynamic angle of repose, $\theta$, measured during the spreading event.

\subsection{METHODOLOGY FOR NUMERICAL MODELING}

\subsubsection{Discrete Element Method for Powder Spreading}

Handling and spreading of powder materials is an integral step of AM. The metal powder contains particles of various sizes and shapes that can vary depending on the handling and reuse of the material. The powder macroscopic response results from the microscopic interaction between the individual powder particles through friction, collision, and cohesive forces. During rapid movements such as in powder spreading, inertial forces are also important. The competition between dissipation, elastic, and inertial forces can create multitude of powder macroscopic responses that are difficult to describe using the methods of continua, either solid or fluid mechanics.

DEM is an alternative approach that models the particulate assemblies by explicitly modeling the underlying particles and their micro-mechanical interactions. While drawing on a simple premise, this approach was not practical until HPC resources enabled modeling of a large number of particles that are representative of the macroscopic behavior of the particle assemblies. DEM is inherently an HPC technology and is increasingly used in industry. The principal strategy for computational acceleration 
using parallelism is by using methods of domain decomposition which allow us to consider the large assemblies of particles, i.e. large volume of powder in AM. However, since the DEM uses explicit time integration schemes, the acceleration of time integration is still an open question and active area of research.

In the DEM code, the metal powder bed is considered as an assembly of discrete entities. The Hertzian contact model with friction [1,2] was used to account for interaction between particles and recoater system. There are various adhesive forces present in particle level such as electrostatic force, Van der Waals force, and metallic bonding. Also, the powder deposition happens in atmospheric conditions in many AM processes such that particle surface condition is highly sensitive to oxidation, contamination and moisturization. However, practically measuring all the relevant forces are difficult and the values vary by a couple of orders due to surface asperity/roughness, contamination, and oxidation $[3,4,5]$. Furthermore, there is little reliable experimental data available for the values of effective cohesive energy in literature. It is concluded that the values of adhesive energies between particles should be calibrated in terms of cohesive energy. The simplified Johnson-Kendall-Roberts (SJKR) model is used to implicitly consider the cohesion force on the basis of Hertzian theory [6]. Additional normal force tending to maintain the contact is calculated using equation (1):

$$
F_{c}=k A
$$

where $\mathrm{k}$ is the cohesion energy density and $A$ is the contact area between spheres.

The particles are simplified as a perfect sphere. Total force acting on a particle consists of contact normal force, contact shear, gravitational force, and cohesion force. Total momentum force is a sum of momentums derived from contact shear and relative particle rotation in between two particles. The total force and momentum force are used to calculate the translational and rotational acceleration using equations (2) and (3). The particle velocities are calculated by integrating these accelerations using leapfrog integration method $[7,8]$ and finally, the displacement and position of discrete particles can be calculated at the end of each time step.

$$
\begin{gathered}
F_{t o t}=F_{c n}+F_{c s}+F_{g}+F_{c}=m \ddot{x} \\
M_{t o t}=M_{c s}+M_{r}=I \ddot{\omega}
\end{gathered}
$$

where $F_{t o t}$ is total force acting on a particle, $F_{c n}$ is contact normal force, $F_{c s}$ is contact shear force, $F_{g}$ is the gravitational force, $m$ is particle mass, $\ddot{x}$ is acceleration velocity of particle, $M_{\text {tot }}$ is total momentum acting on a particle, $M_{c S}$ is momentum caused by shear force, $M_{r}$ is rolling resistance, $I$ is inertial of a particle (e.g. $I=2 / 5 \mathrm{~m} r_{i}^{2}$ ) and $\ddot{\omega}$ is angular acceleration of a particle.

In this work we used the public domain DEM code LIGGGHTS which is an extension of a public domain code LAMMPS $[1,9]$. LAMMPS is a general molecular dynamics software that also has particle short-range mechanical interactions that can be used for modeling granular assemblies. LIGGGHTS expands on the existing DEM capabilities of LAMMPS by adding some features that enable easier handling of moving boundaries and particle mechanical manipulation. Since both codes are following the same input syntax and are under continuous parallel development, they can be used interchangeably with little model modifications. One advantage of the LIGGGHTS is that it supports coupling with the 
computational fluid dynamics (CFD) code OpenFOAM and used for modeling coupled particlecontinuum problems $[1,9]$.

\subsubsection{Calculation of Fabric Tensor}

Fabric tensor is a metric that quantifies microstructural direction-dependent features in tensorial form [10]. The fabric tensors can be constructed from interparticle contact vectors in the particle assembly or powder bed. Since the particles are assumed as spheres and soft contact [11] in DEM simulation, the contact vector can be calculated from the area where two random sphere particles are in contact. By comparing the center to center distance of two particles to the sum of the two radii, Figure 5, the contact area and contact normal vector can be identified in DEM simulation.

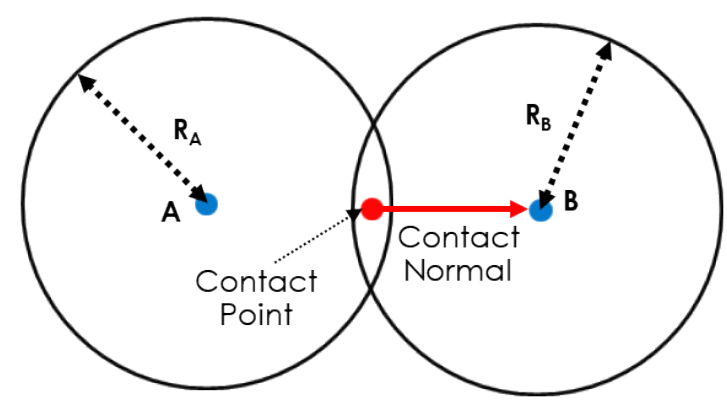

Figure 5. Illustration of spheres in contact showing contact normal vector.

Three kinds of fabric tensors have been developed to describe and characterize the directional datasets (i.e. orientations of each particle) of random packing [10, 2]. In this report, the fabric tensor of second and fourth rank was used to quantify the directionality of interparticle contacts in the powder bed. The second and fourth rank fabric tensors are defined as below:

$$
\begin{aligned}
& N_{i j}^{(2)}=\frac{1}{N} \sum_{a=1}^{N} n_{l}^{(a)} n_{j}^{(a)}, N_{i j}^{(4)}=\frac{1}{N} \sum_{a=1}^{N} n_{i}^{(a)} n_{j}^{(a)} n_{k}^{(a)} n_{l}^{(a)} \\
& F_{i j}^{(2)}=\frac{15}{2}\left(N_{i j}^{(2)}-\frac{1}{5} \delta_{i j}\right), F_{l j}^{(4)}=\frac{315}{8}\left(N_{i j}^{(4)}-\frac{2}{3} \delta_{i j} N_{i j}^{(2)}+\frac{1}{21} \delta_{i j} \delta_{k l}\right) \\
& D_{i j}^{(2)}=\frac{15}{2}\left(N_{i j}^{(2)}-\frac{1}{3} \delta_{i j}\right), D_{l j}^{(4)}=\frac{315}{8}\left(N_{i j}^{(4)}-\frac{6}{7} \delta_{i j} N_{l j}^{(2)}+\frac{3}{35} \delta_{i j} \delta_{k l}\right)
\end{aligned}
$$

where $N_{i j}$ is the fabric tensor of the first kind referred to as moment tensor, $N$ is number of directional data, $n$ is directional data (i.e. contact vector in this report), $F_{i j}$ is the fabric tensor of the second kind referred as fabric tensor, $\delta_{i j}$ is Kronecker delta and $D_{i j}$ is the fabric tensor of the third kind referred to as deviatoric tensor. The moment tensor is the average of unit vectors. This tensor plays a key role in deriving tensor quantities characterizing the contact distribution. The fabric tensor is a coefficient tensor and describes the distribution function of directional dataset. The deviatoric tensor is also a coefficient tensor determined by the least-square error method.

In this report, the directionality of contact vectors is our only interest such that the unit vectors of the contact vectors are used for the calculation of the fabric tensor. Once the contact vectors are found, the fabric tensor can be visualized using the rose diagram which is frequency histograms plotted in a polar 
coordinate system $[12,13,2]$. For the visualization, MATLAB's software package MMTensor [14] was used. Literature has broadly reviewed the fabric tensor in granular materials, but this method has not been popular in the AM community to date.

\subsubsection{Model Setup}

AOR test has been extensively used to calibrate and validate the DEM simulation [3]. The computation domain for the AOR simulation was set within the dimensions of $6 \mathrm{~mm}(\mathrm{~L}) \times 3 \mathrm{~mm}(\mathrm{~W}) \times$ $1.8 \mathrm{~mm}(\mathrm{H})$ in Figure 5. 105,000 particles are inserted into the rectangular box using the raindrop method, and approximately half-filled. $10 \times 10 \times 10 \mathrm{~mm}$ reservoir was placed beneath the rectangular box to collect the fallen particles in Figure 6. Particle size is in the range of approximately $14 \mu \mathrm{m}$ to $50 \mu \mathrm{m}$ in radius. The bottom plate slides out to the left side of the system to allow particle-drop under the action of gravity.

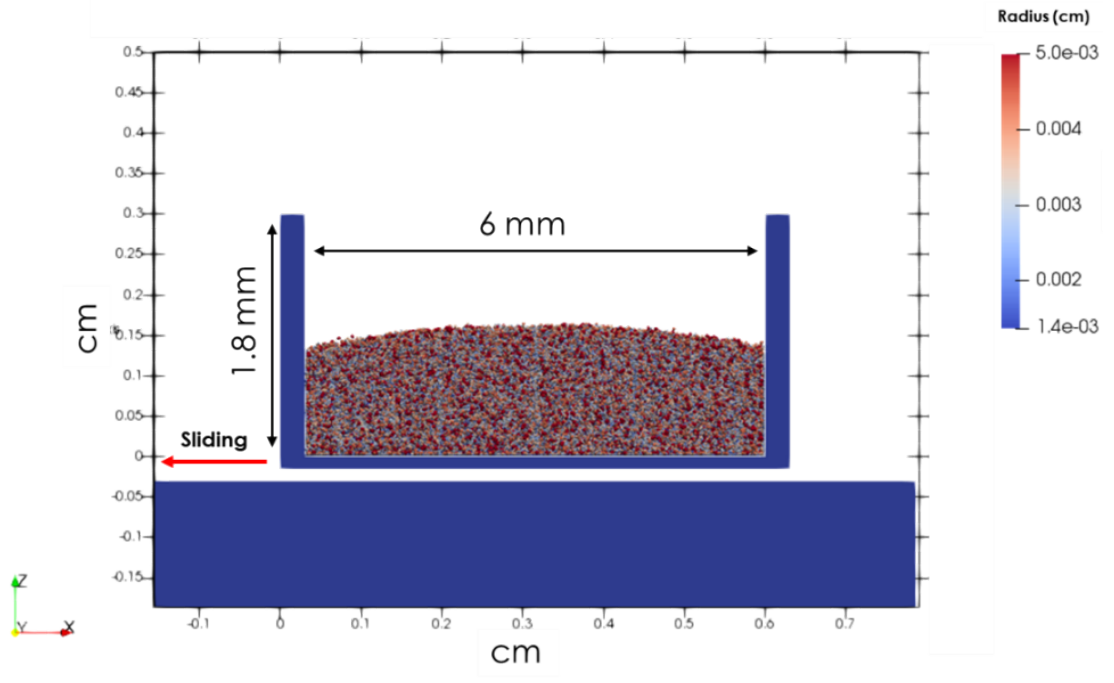

Figure 6. Simulation setup for AOR prediction, 105,000 particles are filled with half of the box and fall as the bottom plate slides out.

The particle spreading process distinguishes between the DEM simulation for powder bed AM and a typical particle packing simulation since the interaction between recoater and particles changes the quality of the powder bed [15]. Figure 7 shows the geometry of the powder spreading simulation before adding the particles. The simulation has the dimensions of $18.9 \mathrm{~mm}(\mathrm{~L}) \times 3 \mathrm{~mm}(\mathrm{~W}) \times 1.8 \mathrm{~mm}(\mathrm{H})$ for the spreading plate. The recoater thickness is $0.5 \mathrm{~mm}$ and has an angle of $10^{\circ}$ at the bottom edge, which are the values used in the experiment. The particles are inserted into the front of the rake at every layer deposition step. The spacing between rake and the plate was set to be $102 \mu \mathrm{m}$ or $508 \mu \mathrm{m}$ depending on the experimental setting. 


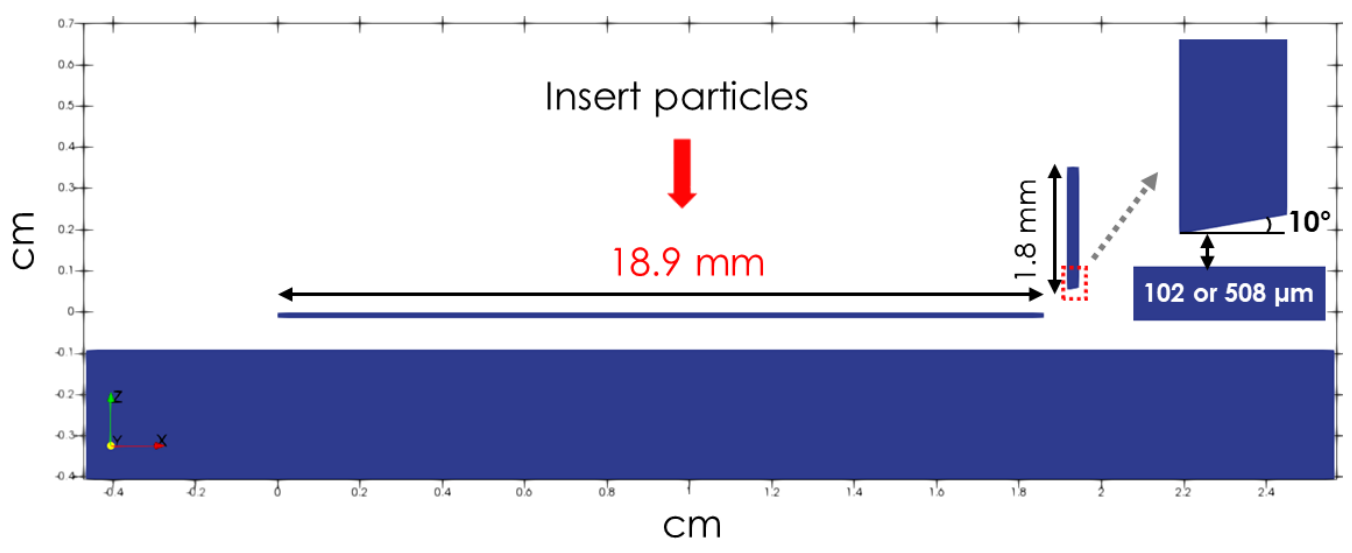

Figure 7. Computation domain for powder spreading simulation.

\subsubsection{Workflow for simulations of spreading of multiple layers}

In this study, the multi-layer spreading simulation consists of two steps: 1) generation of initial particle pileup, and 2) spreading the particles using recoater. The workflow to simulate multiple layer spreading process is given in Figure 8. The initial particle pile in Figure 8(a) was generated using the raindrop method, in which particles fall because of gravity. After the particles become stabilized, the information of individual particles including $\mathrm{x}, \mathrm{y}, \mathrm{z}$ coordinates and radius was exported from the particle generating system and imported to the actual spreading system including rake in Figure 8(b). It is reasonable simplification because the shape of particle pileups is similar or the same at every drop. In practice, since the particles are poured at the beginning of every spreading step or moved from powder reservoir, this method can significantly reduce the total computation time used for particle drop and settlement or moving. The insertion of initial particle pile is shown in Figure 8(b) and (d). The creation of first and next layer are shown in Figure 8(c) and (e). 


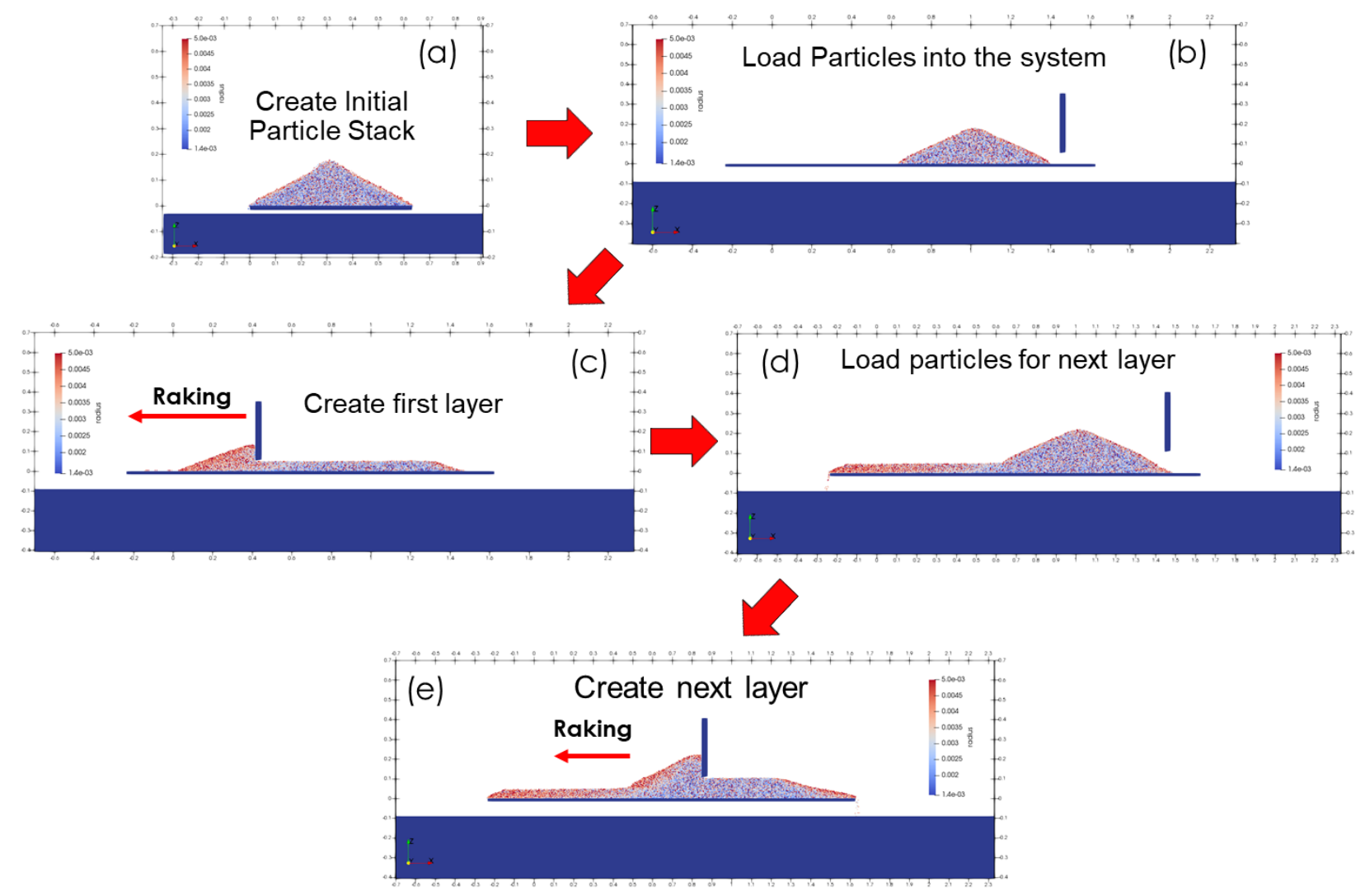

Figure 8. Workflow to model the layer deposition process. The initial particle stacks in (a) are inserted at every beginning of the deposition, (b) and (d) which method significantly reduces the total computation time. The spreading steps are shown in (c) for the first and (e) for the second layer.

\subsection{EFFECT OF PARTICLE SPREADING DYNAMICS ON POWDER BED QUALITY}

\subsubsection{Modeling and Calibration of the Angle of Repose}

AOR is a widely accepted method to calibrate and validate the particle properties. We analyzed the interactions of particle to particle and particle to manufacturing systems involving static friction, rolling forces, restitution, and cohesive forces in terms of AOR. Obtaining all particle properties may not be feasible experimentally [3, 4]. For instance, the cohesion energy between particles and particle-system is not only difficult to measure but also varies by a couple of orders due to surface roughness, contamination, and oxidation $[3,4]$. The base values of particle properties were assumed to be restitution $(=0.1)$, static friction $(=0.4)$, rolling $(=0.05)$ and cohesion force $(=3.2 \mathrm{e}+7$ unit).

AOR and powder spreadability rely heavily on the interactions of particles to particle and particle to wall in the system. The effect of friction and rolling coefficient on AOR was investigated in Figure 9. The coefficient of static friction and rolling is increased by 1.5 times in Figure 9(a) and three times in Figure 9(b) respectively. The angle becomes $28.8^{\circ}$ and $29.0^{\circ}$ at cohesion force of 3.2e+7. It indicates that both coefficients contribute little to the increase of the angle. 

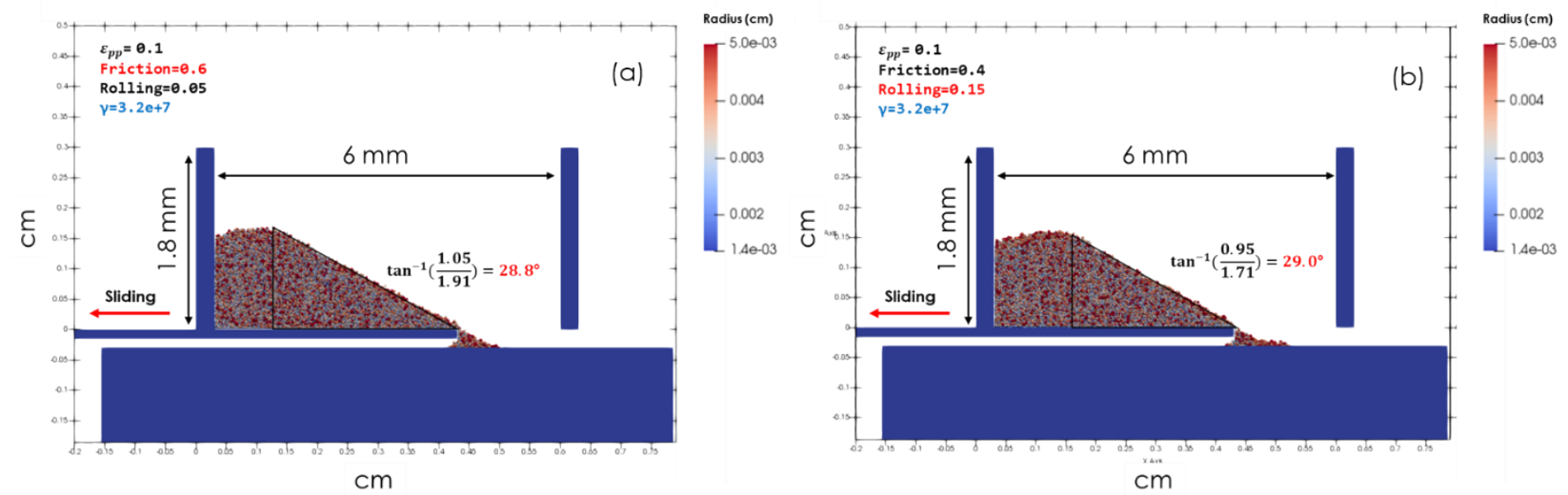

Figure 9. Effect of static friction and rolling coefficient on AOR. Both coefficients showed little influence on the change of AOR.

Since the cohesion force has strong influence on AOR [3], cohesion force is varied from $3.0 \mathrm{e}+7$ to 3.6e+7. Figure 10 shows that AOR increases from $28.9^{\circ}$ to $32.1^{\circ}$ as the values of cohesion force increase from $3.0 \mathrm{e}+7$ to $3.6 \mathrm{e}+7$. Notice that the predicted AOR is $32.1^{\circ}$ at cohesion force of $3.6 \mathrm{e}+7$ which is in good agreement with the measured AOR of $33.0^{\circ}$.
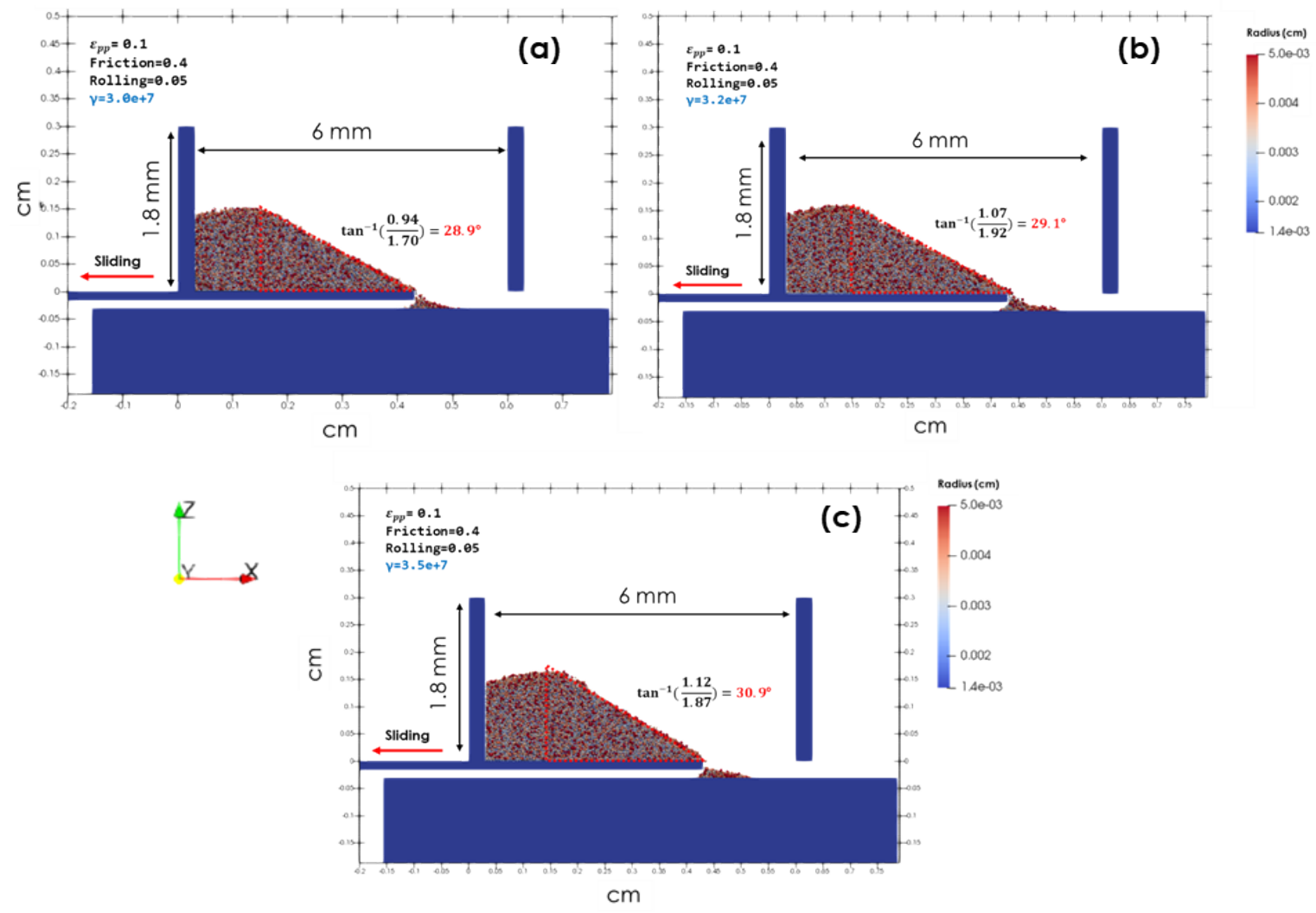

Figure 10. The predicted AOR with particle cohesion energy (a) 3.0e+7, (b) $3.5 \mathrm{e}+7$ and (c) $3.6 \mathrm{e}+7$ that shows the best match with the measured value of $33.0^{\circ}$. 


\subsubsection{Formation of Deposit Layers}

The powder bed thickness varies with the layers in Table 1 . The first two layers have $508 \mu \mathrm{m}$, and the next two layers have $102 \mu \mathrm{m}$ and $127 \mu \mathrm{m}$ layer thickness, respectively. The gap spacing between the rake and spreading plate should be adjusted every layer in correspondence to the specified bed height in the experiment. The predicted and experimentally measured bed height were compared at every layer in Figure 11. The predicted results are well agreed with the measured within $1 \%$ error range.

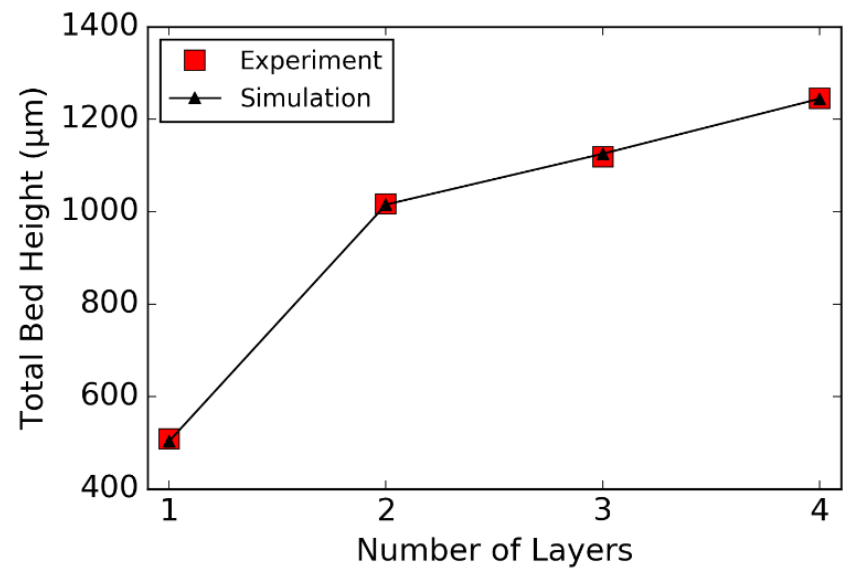

Figure 11. Validation of the predicted powder bed height. The bed height matches well with the experiment. The predicted bed height matches with the measured height (in Table 1) within $1 \%$ error range.

\subsubsection{Dynamic Angle of Repose}

In powder bed AM process, particles with good spreadability are beneficial to form defect-free layer. AOR may be insufficient to describe the particle dynamic behavior during spreading since it captures the angle in static equilibrium state. However, dynamic AOR accounts for interactions between particles and recoating systems such that it captures transient variation in particle motion. Figure 12 shows the evolution of AOR and pile geometry with time at third layer. In Figure 12(a), the dynamic AOR is almost constant overall in both experiment and simulation. There are little fluctuations present because of particle random motion. Notice that there is an abrupt increase of the angle at the beginning of the spreading stage in experiment. It indicates that there is a strong resistance against forwarding motion. Then, the strong bonding is broken by the rake and the angle becomes consistent. It can be explained that the experiment was carried out in atmospheric conditions that possibly contains moisture. The simulation is not able to capture the change of the moisture. After the breakage, however, the model reasonably well predicts the variation of dynamic AOR. Figure 12(b)-(d) shows the characteristic shape of powder piles from the results of both simulation and experiments. The volume of the pile progressively decreases as the powder pile is moved by rake from (d) right to (b) left region of the plate. It is because the particles are consumed to form the powder layer. Flat toe region appears at the top of the powder pile in both simulation and experiment in Figure 12(d) and disappears as the particles are consumed in Figure 12(b). The DEM simulation captures well the appearance and disappearance of flat toe region. 

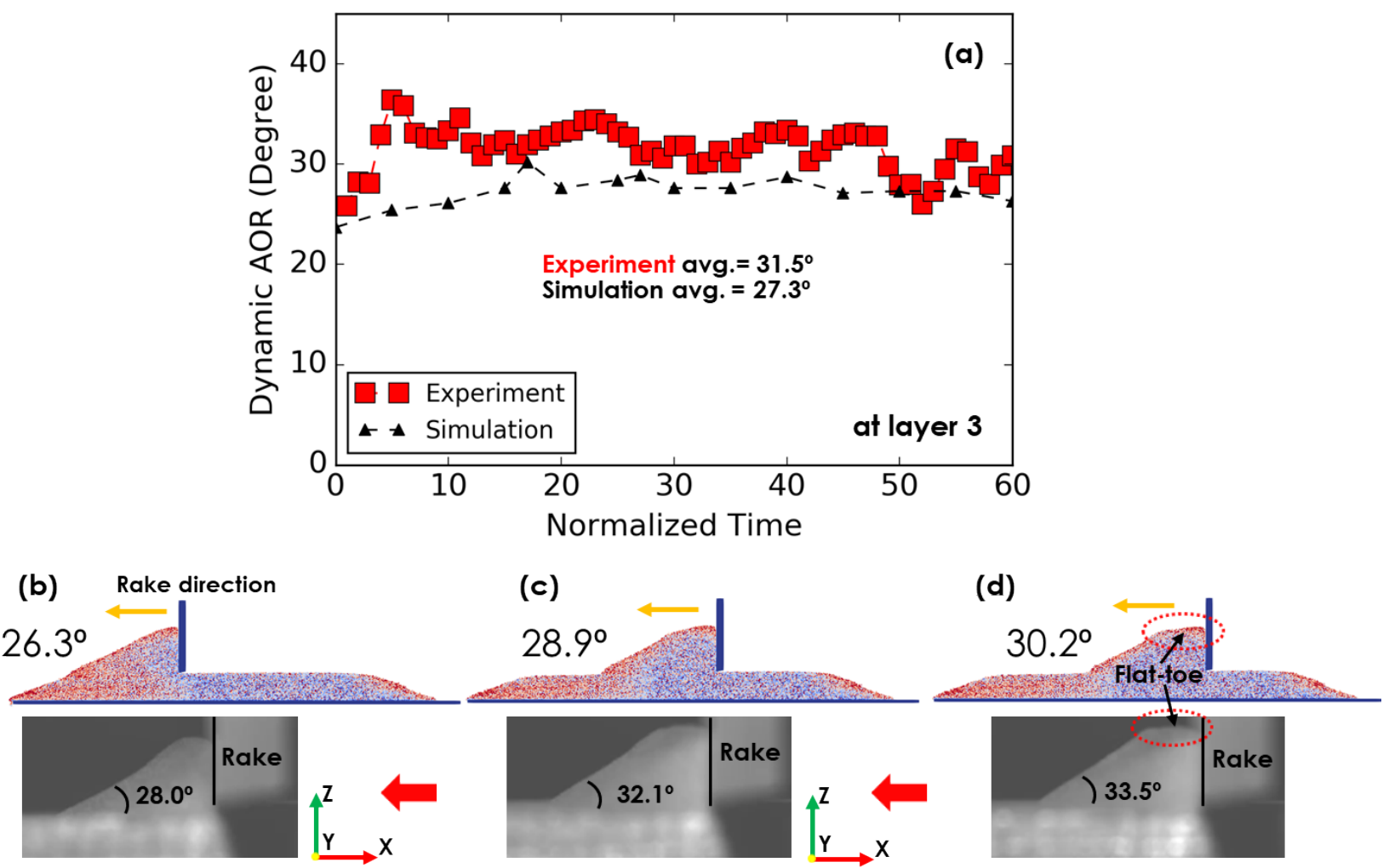

Figure 12. Comparison of dynamic AOR with experiment, (a) Evolution of dynamic AOR with time, (b)-(d) Characteristic geometry of powder pile compared with experimental images.

Smaller dynamic AOR indicates better spreadability of powder particles during layering stage [16]. Figure 13 shows the evolution of the dynamic AOR with rake velocity. Rake velocity was increased by $\times 2$ and $\times 5$ times from the default velocity of $2.54 \mathrm{~cm} / \mathrm{s}$. In general, the dynamic AOR increases with increase of rake velocity from $27.3,29.6$ to $38.3^{\circ}$. Also, a higher gradient of the angle variation was observed with the increase of the rake velocity. These increases imply that higher rake velocity possibly decreases the spreadability of particles. Consequently, the inferior quality of powder bed can be developed at high rake velocity (e.g. poor surface roughness and low packing density). 


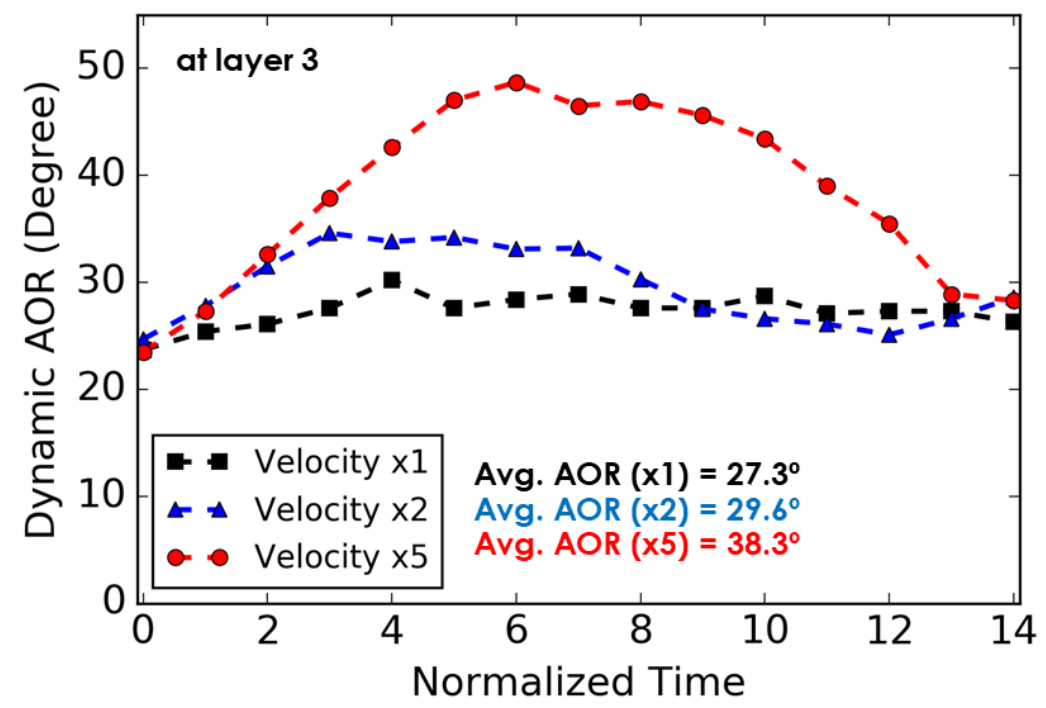

Figure 13. Evolution of dynamic AOR with rake velocity. High velocity increases the dynamic AOR and the gradient of angle variation.

\subsubsection{Influence of Rake Velocity on Powder Bed Quality}

\subsubsection{Variation of packing density}

Packing density is one of the critical parameters influencing powder bed quality. It is reported that a higher packing density is favorable to produce denser parts with better surface finish [8]. The packing density is defined as the ratio of the total volume of the particles to total volume of the box enclosing all of the particles. Figure 14(a) shows the variation of packing density with the change of rake velocity at the first layer. The density was decreased by about $5 \%$ as the rake velocity increases by five times. Figure 14(b) shows the change of surface quality at different rake velocities. The velocity of $\times 1$ produces fairly uniform surface while the velocity of $\times 5$ generates unfilled and non-uniform surface at the left side of powder bed. It confirms that higher rake velocity highly produces poor surface finish. 


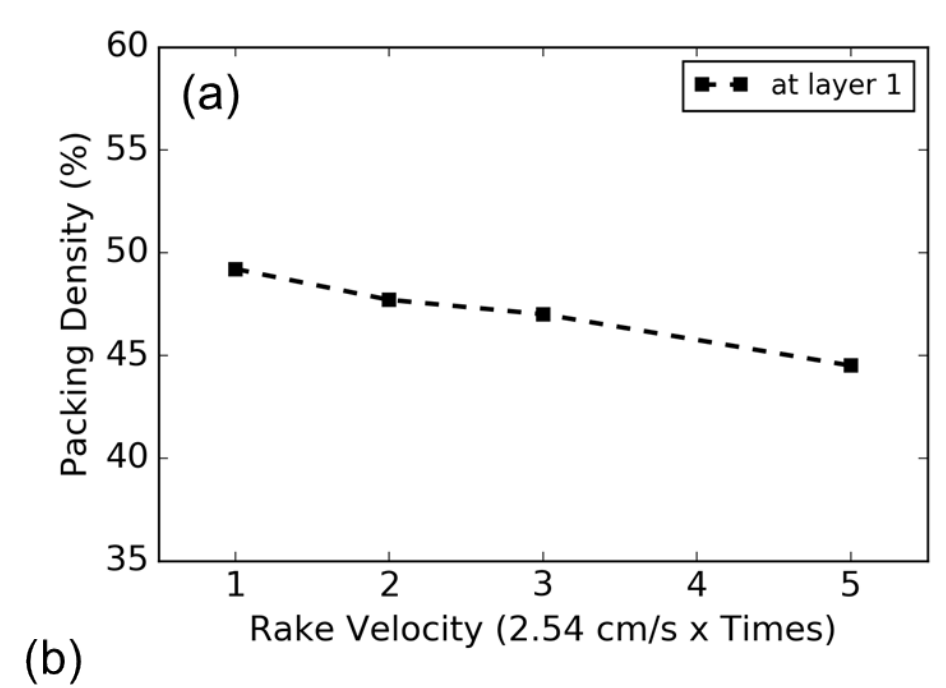

(b)

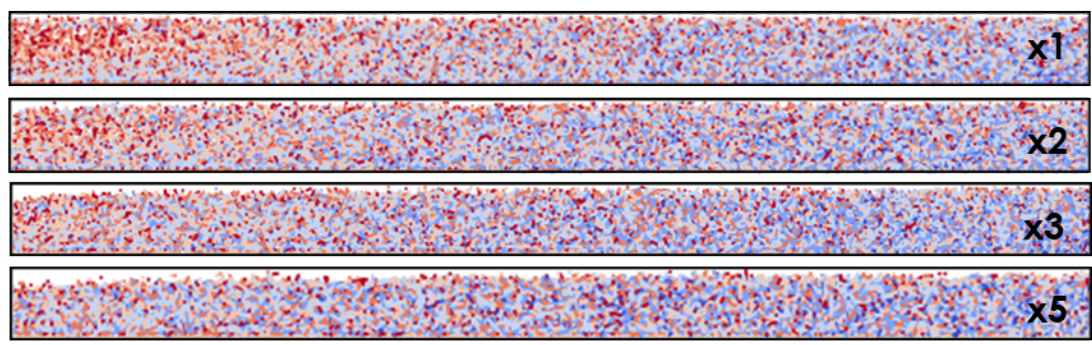

Figure 14. Variation of (a) packing density and (b) surface roughness with rake velocity.

\subsubsection{Particle segregation}

Figure 15 shows the predicted PSD (a) before spreading and (b) during deposition. The particles are uniformly mixed at the initial particle pile while coarser particles are observed in the particle pile at the rake front during deposition. The thicker radish color indicates that there is more ratio of coarser particles present in the pile in Figure 15(b). Comparison of the measured PSD with the predicted PSD at before spreading and after spreading was made in Figure 15. The PSD before spreading is the same as the measured one. However, as the rake moves the particles to the end of plate, the PSD shifts toward the right region (=coarser region). It indicates that particle segregation occurs by the interaction between particle and rake system. The particle segregation was recently reported in the AM experimental literature $[17,18,19]$. The author hypothesized that dynamic particle-recoater interaction can lead to particle segregation during particle spreading stage. The segregation possibly causes inhomogeneous packing density in the powder bed. Consequently, it increases a chance of generating defects during melting process. 
(a) Initial pile-ups
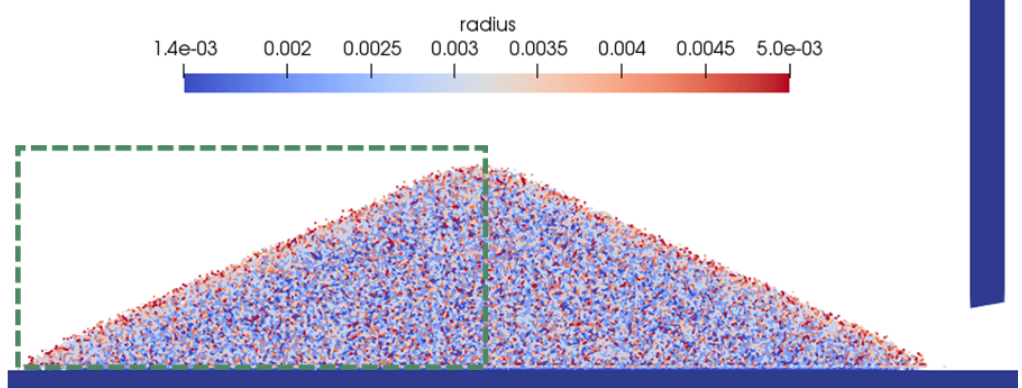

(b) During deposition

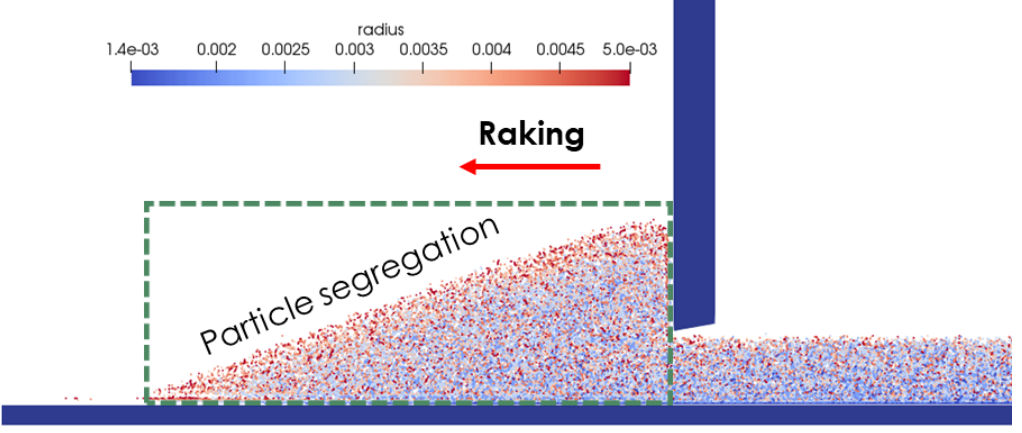

Figure 15. Particle segregation on the top surface of the powder stack front

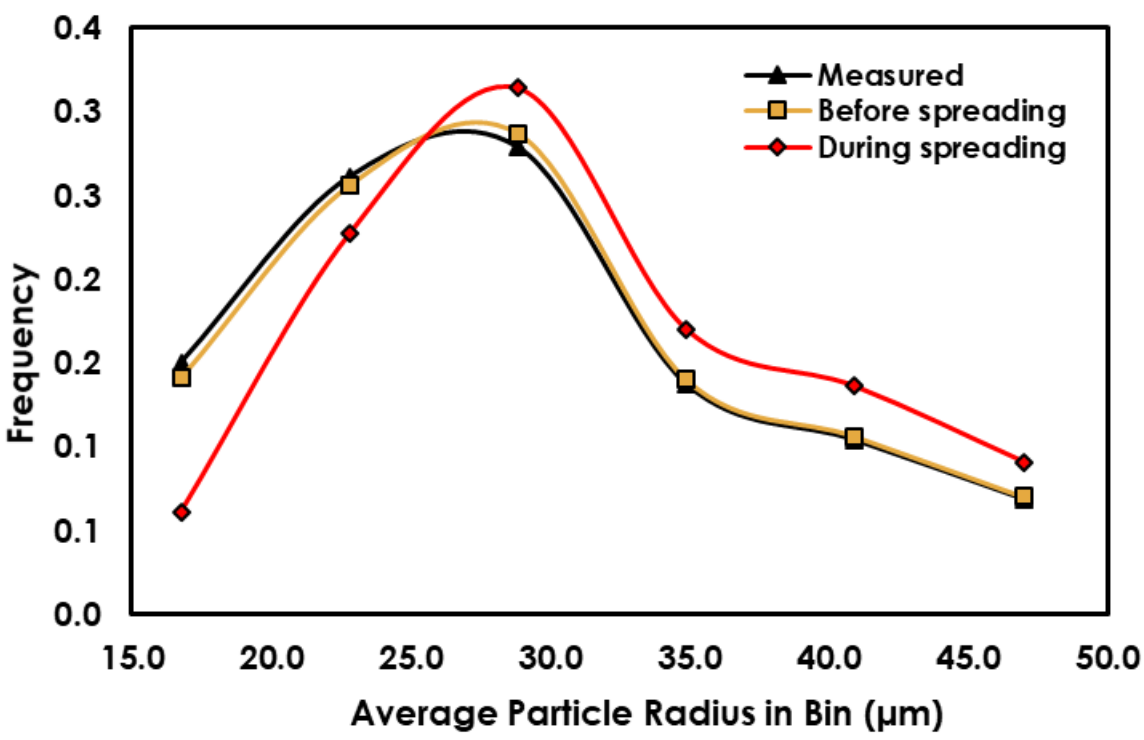

Figure 16. Comparison of the measured PSD with the predicted PSD at before spreading and after spreading.

PSD is one of the indicators to determine the powder bed quality. The influence of recoating systems on PSD should be investigated to optimize the system for acceptable part quality. Figure 16 shows the variation of PSD in the first layer as a function of rake velocity. The values of particle radius are taken from the left half of the powder bed after the raking is completed. Note that PSD shifts to a finer region as 
increasing rake velocity. As seen in Figure 15 and 16, the coarse particles are segregated to the front of the moving pile. This may drive the PSD shift to coarser particle region at lower rake velocity. In other words, higher rake velocity leads to stronger mixing of particles. The PSD shifts to finer region. This shows that particle segregation should be alleviated to achieve desired final part properties.

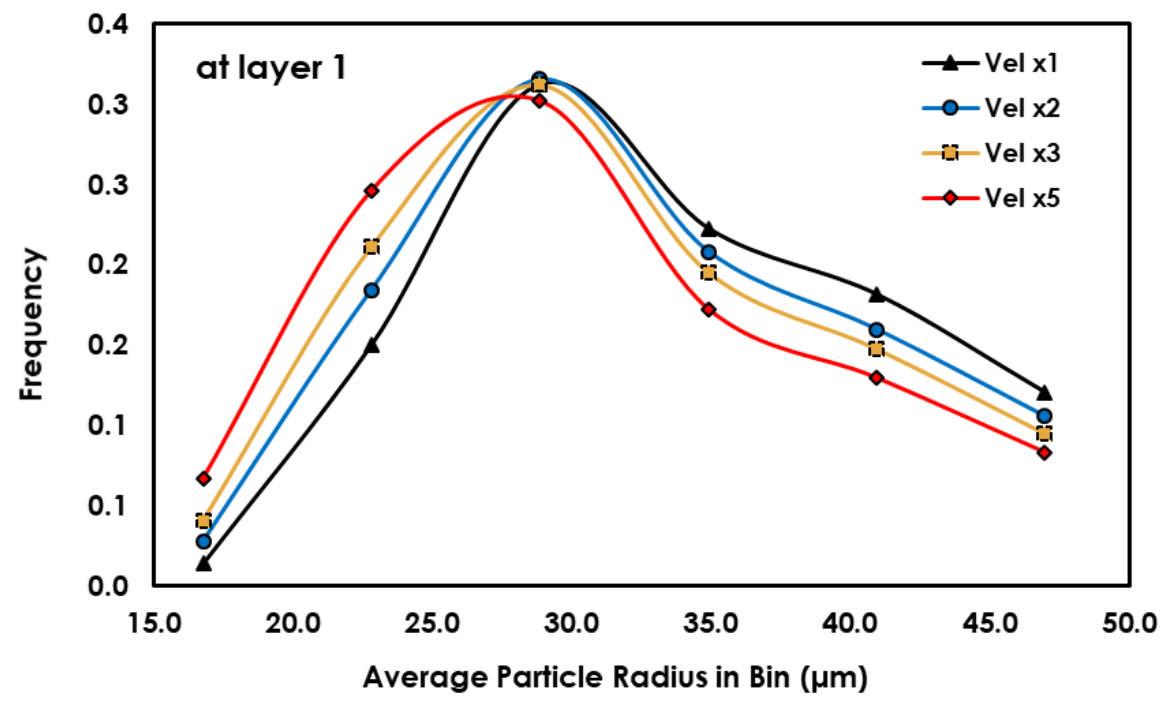

Figure 17. A shift of PSD as a function of rake velocity. Higher rake velocity drives PSD shift to finer region.

\subsection{QUANTIFICATION OF POWDER SPREADING PROCESS}

\subsubsection{Scalar methods: Packing Density, Coordination Number, Particle Size Distribution}

Coordination number $(\mathrm{CN})$ varies with densification level from loose packing to full densification. Material properties such as green part strength, thermal and electrical conductivity are typically proportional to packing density (PD) and CN. Thus, knowing the relationship between PD and $\mathrm{CN}$ is critical to the powder particle associated processes including sintering, hot isostatic pressing, and powder bed fusion AM. The mathematical relationship was established in powder metallurgy literature using a semi-empirical formula of equation (7) [20].

$$
C N_{S}=2+11 f^{2}
$$

Evolution of average $\mathrm{CN}$ in the powder bed AM is shown in Figure 18. Roller compresses the particles in a forward and downward direction. The average $\mathrm{CN}$ increases from approximately 2.5 to 4.0 because of the interaction with the recoater systems. It shows that the number of interparticle contacts increases as the roller moves at the beginning of the spreading process. 


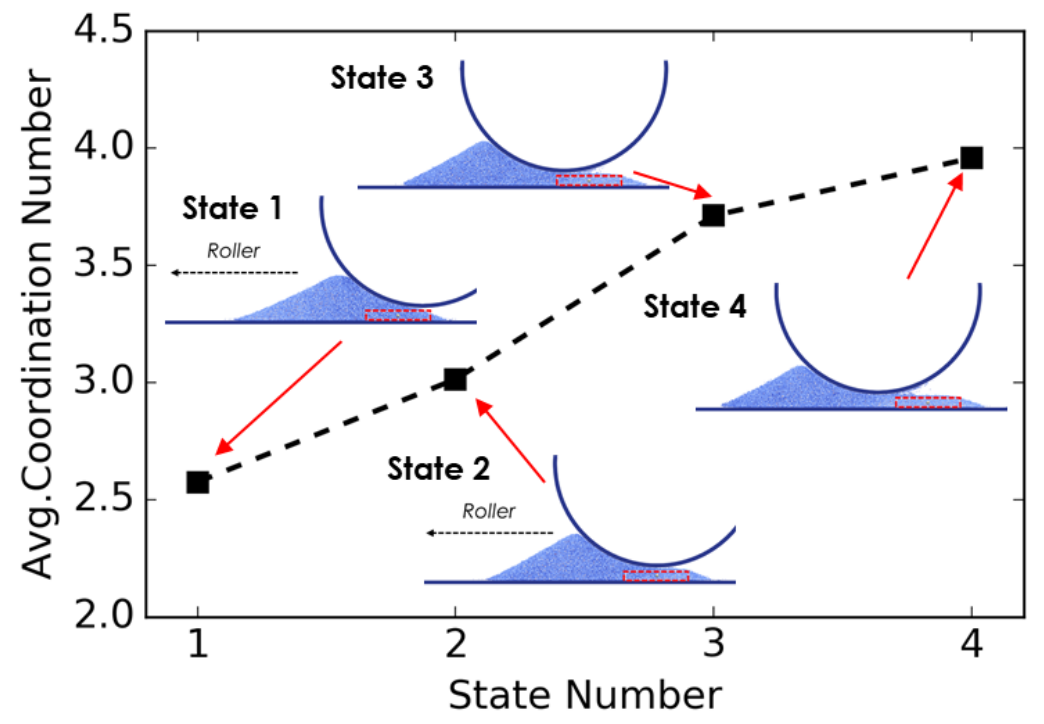

Figure 18. Evolution of average coordination number because of interaction with recoater system. Roller compresses the particles and increases interparticle contact at the beginning of the spreading process.

Figure 19 shows the influence of recoater velocity on $\mathrm{CN}$. Two types of recoater (i.e., rake and roller) were used for powder spreading. $\mathrm{CN}$ changes by approximately 0.2 in the given velocity range of 2.54 $\mathrm{cm} / \mathrm{s}$ to $12.54 \mathrm{~cm} / \mathrm{s}$ for both types of recoater. This minor change shows that the effect of recoater geometry can be neglected in $\mathrm{CN}$.

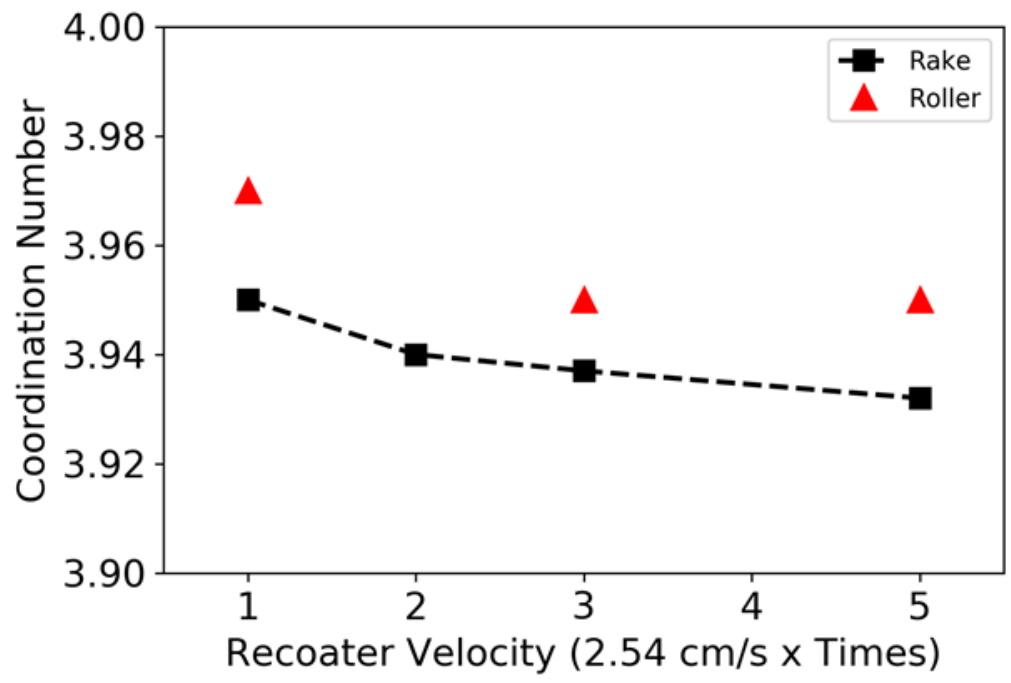

Figure 19. Variation of overall coordination number $(\mathrm{CN})$ in the powder bed at different recoater velocities. Change of recoater geometry shows little effect on $\mathrm{CN}$.

As seen, $\mathrm{CN}$ can be correlated with PD. The $\mathrm{CN}$ was first estimated using equation (1) based on the predicted PD. The estimated CN is deviated by 0.46 from the predicted CN. For a better link between PD and $\mathrm{CN}$ in DEM simulation, we suggest a new conversion equation (8) with adjusted coefficients of $a=1.925$ and $b=0.04545$. Figure 20 shows that the ultimate estimation and DEM prediction are well agreed after the coefficient calibration. Although packing density (on red solid line) decreases by 
approximately $5 \%$ with increase of rake velocity, the change of $\mathrm{CN}$ is 0.2 and it may be too small to experimentally measure. Furthermore, the PD and CN relationship is sensitive to several factors such as particle types, size, and adhesion conditions. This implies that powder bed quantification can be reinforced by numerical analysis.

$$
C N_{m}=2 a+11 b f^{2}
$$

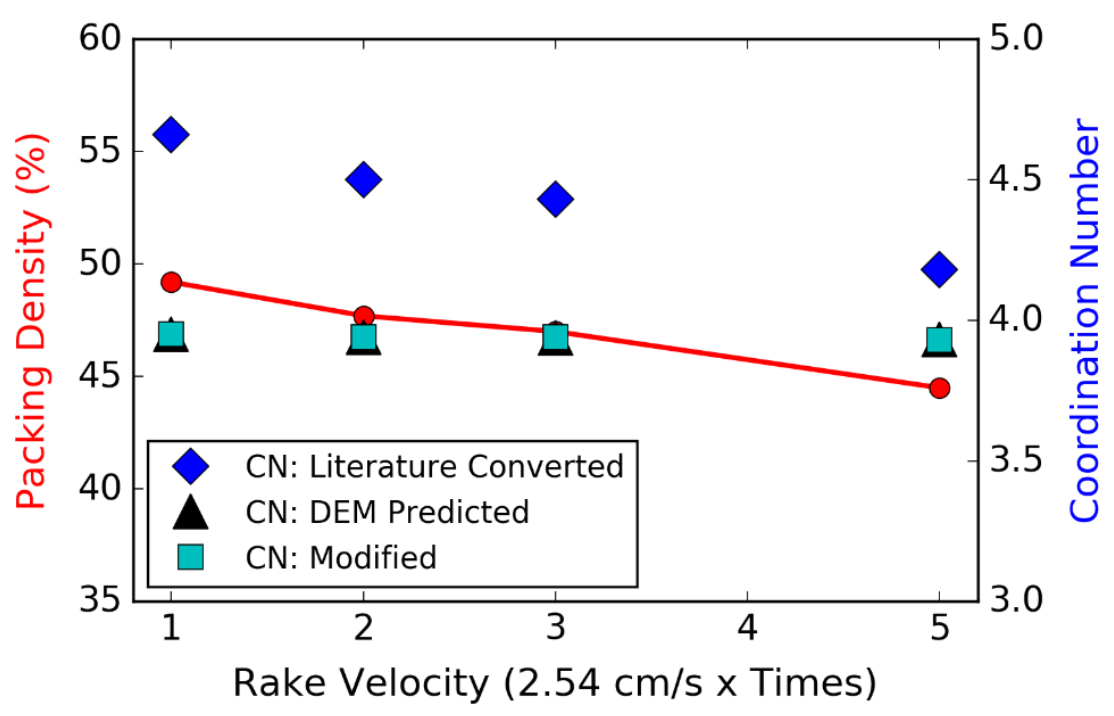

Figure 20. Correlation of overall packing density with overall coordination number (CN) as a function of rake velocity.

Figure 21 shows a local variation of PD and $\mathrm{CN}$ at the rake velocity of $2.54 \mathrm{~cm} / \mathrm{s}$. PD is the highest at the start and decreases by $3.5 \%$ as the rake goes to the end of the powder bed. In general, PD decreases with $\mathrm{CN}$ as the interparticle attractive force increases [20]. Interestingly, the highest $\mathrm{CN}$ is found at the center rather than the start region where the PD is not the highest. This inconsistency implies that particles interact with the recoater system and rearrange the packing order and interparticle contacts on a local scale. Recall that the change of $\mathrm{CN}$ was subtle in the overall scale but there are noticeable variations observed in the local region of powder bed. This inhomogeneous distribution in CN and PD potentially leads to non-uniform heating, melting, and boding in part building steps.

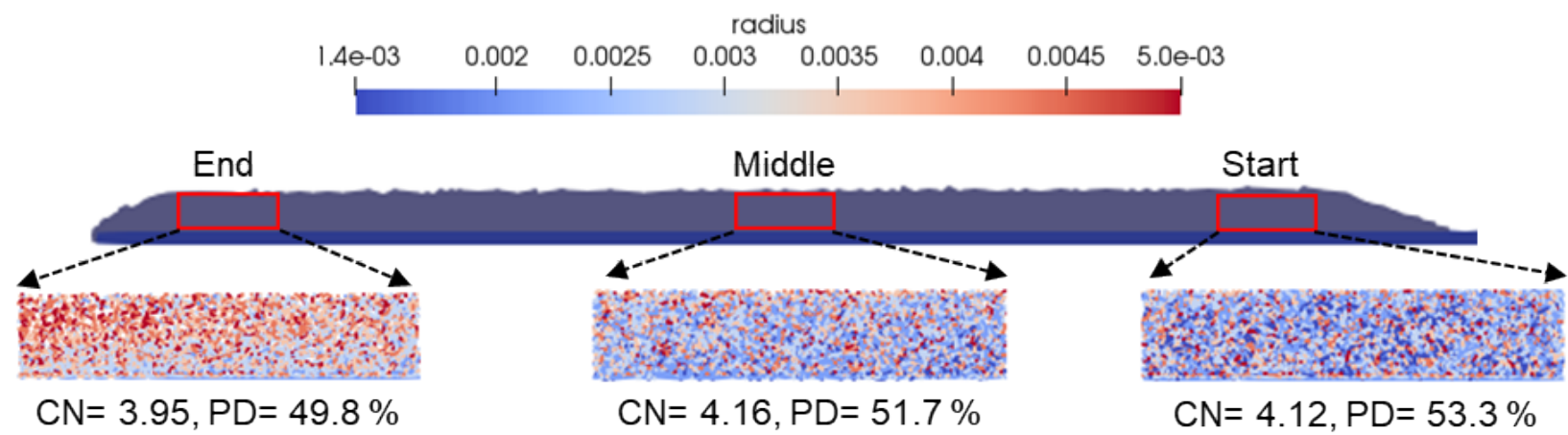

Figure 21. Local variation of packing density (PD) and coordination number (CN) at rake velocity of 2.54 $\mathrm{cm} / \mathrm{s}$. Interaction of particles with recoater system leads to change of powder bed configuration. 


\subsubsection{Tensorial Method: Orientation of Inter-Particle Contacts}

In metal AM, particles are heated and melted (or sintered) by a heat source such that knowing heat transfer direction makes the process more controllable. Heat transfer in the powder bed primarily occurs through contracts between particles [21]. The recoater pushes and spreads the particles forwards and downwards and consequently it breaks the initial shape of the particle pile and alters the position of particles. It potentially rearranges the location and direction of the interparticle contacts. The rose diagram is commonly used in geology [13] and it can be used to visualize the fabric tensor quantifying anisotropy of interparticle contracts in frequency and orientation. Figure 22 shows the rose diagram for the (a) second-, (b) fourth-order fabric tensor, and the (c) difference between the tensors at the different powder bed locations of start, center and end. Figure 22(c) shows that fourth-order fabric tensor has more dimpled top and side faces than second-rank tensor. It directs that there are less interparticle contacts at the top and the sides in the fourth-rank representation, which indicates the additional geometrical complexity present in the fort-rank tensor. It concludes that second-order fabric tensor is insufficient to characterize the directionality of interparticle contacts with details. In general, the spherical shape indicates near-uniform distribution in interparticle contacts. An evident alignment was found along y-axis at the start region in both second and fourth order. The alignment becomes weaker at the center region and develops directionality again as the rake moves to the end region.
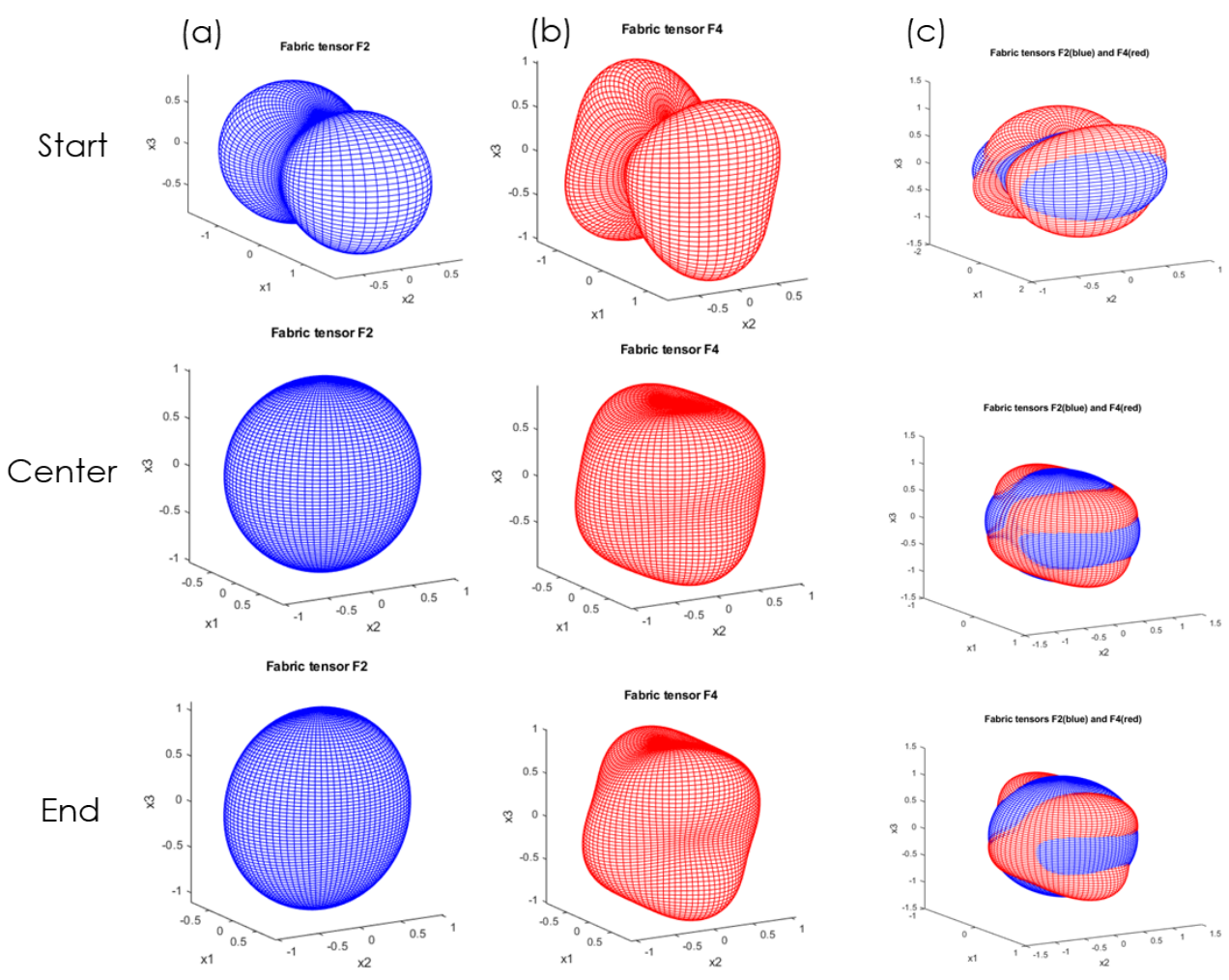

Figure 22. Fabric tensor plot using rose diagram with (a) second and (b) forth-order tensors. The difference between the second and fourth-order fabric tensors shows that the fourth order provides an additional detailed description of interparticle contacts in the powder bed. 
The fabric tensor analysis in this study is used to understand the influence of spreading process parameters on the directionality of interparticle contacts. The evolution of the rose diagram is represented at the start, center, and end region of the powder bed. The difference of two fabric tensors is plotted to visualize the evolution of interparticle contacts at rake velocity of $\times 1$ and $\times 5$ in Figures 23 and 24, respectively. The blue color denotes the reduction of frequency in contacts while red (or yellow) represents the increase of the contract frequency along the directions. The evolution of interparticle contracts is plotted in 3-D and $x-y$ plane, $x-z$ plane. There are some variations found in shape, orientation, and magnitude from each region. In Figure 23(a), the interparticle contact density decreases in y-direction with increase in $\mathrm{x}$-direction. In Figure 23(b), the trend is even more pronounced in magnitude. Notice that the positive distribution (in red and yellow color) rotates about $45^{\circ}$ compared to that in Figure 23(a). It indicates that the particle contacts are shifted forward and rotated as the rake moves from the start to end. In Figure 23(c), the rearrangement in the center-end region is not as strong as in the start-center or startend region.

(a) Start-Center
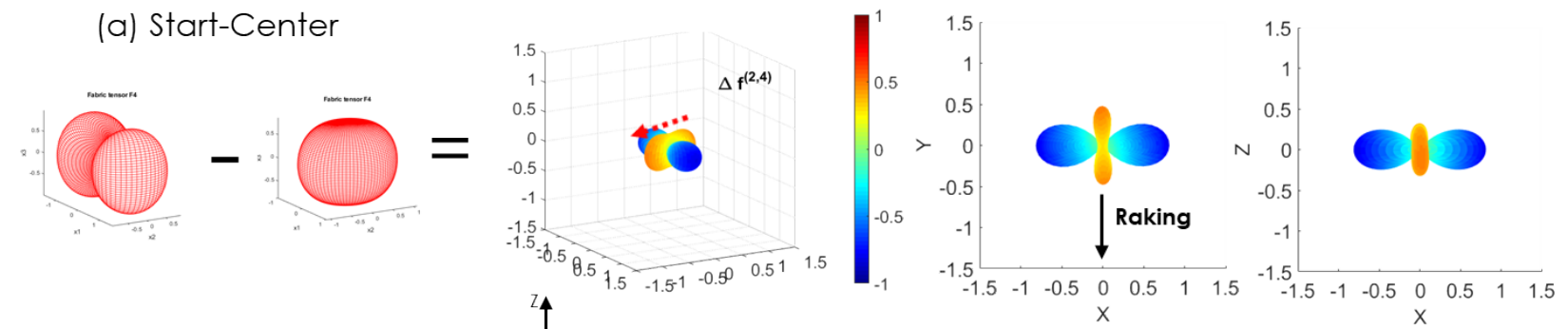

(b) Start-End
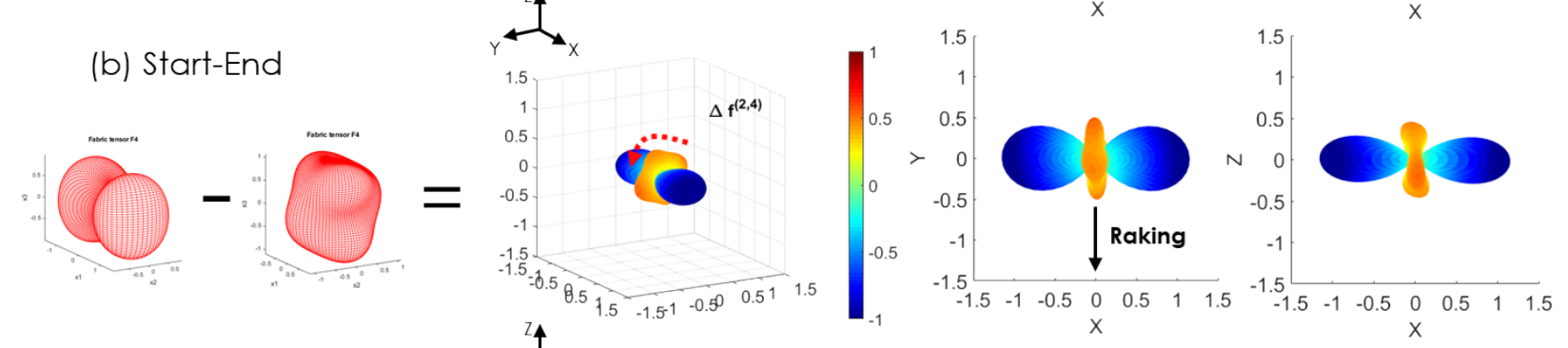

(c) Center-End
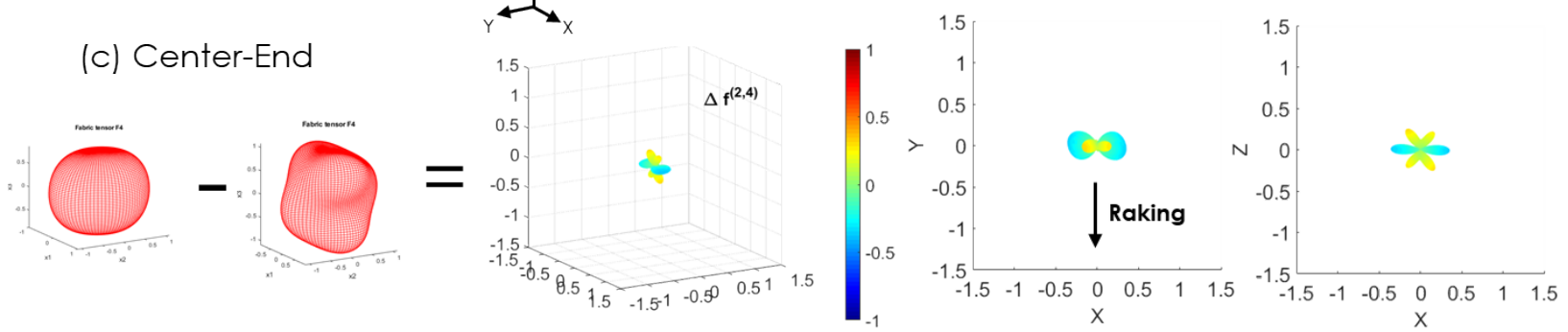

Figure 23. Evolution of fabric tensor at rake velocity $\times 1$.

Figure 24 shows the evolution of interparticle contacts at rake velocity of $\times 5$. The overall trend is almost identical to that at $\times 1$ rake velocity. The positive distribution increases in raking direction (along $\mathrm{x}$-axis) and a negative distribution becomes stronger in transverse direction. However, it is not likely that the shift of interparticle contacts at $\times 5$ rake velocity is as strong as that in Figure 23 . At the beginning of the spreading step in Figure 24(a), the particle contacts are immediately pushed forward and rotated with some degree because of higher translational velocity which has a nature of breaking and mixing the particles than ordering them. Figure 24(b) confirms that the shift in magnitude of particle contacts at the 
higher rake velocity is not as strong as that at the lower rake velocity in Figure 24(b). Since the distribution of interparticle contacts is similar at the center and end region, the rearrangement action is minimal in Figure 24(c).

(a) Start-Center

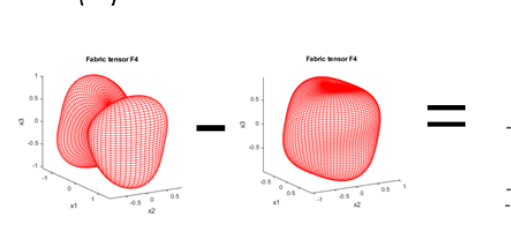

(b) Start-End

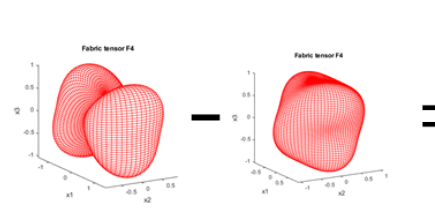

(c) Center-End

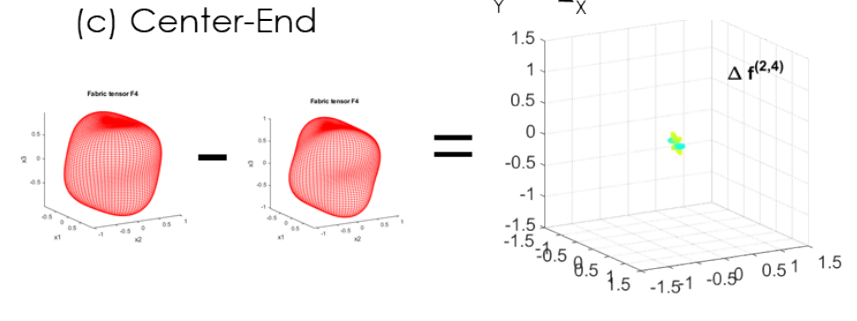

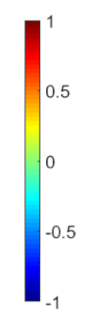
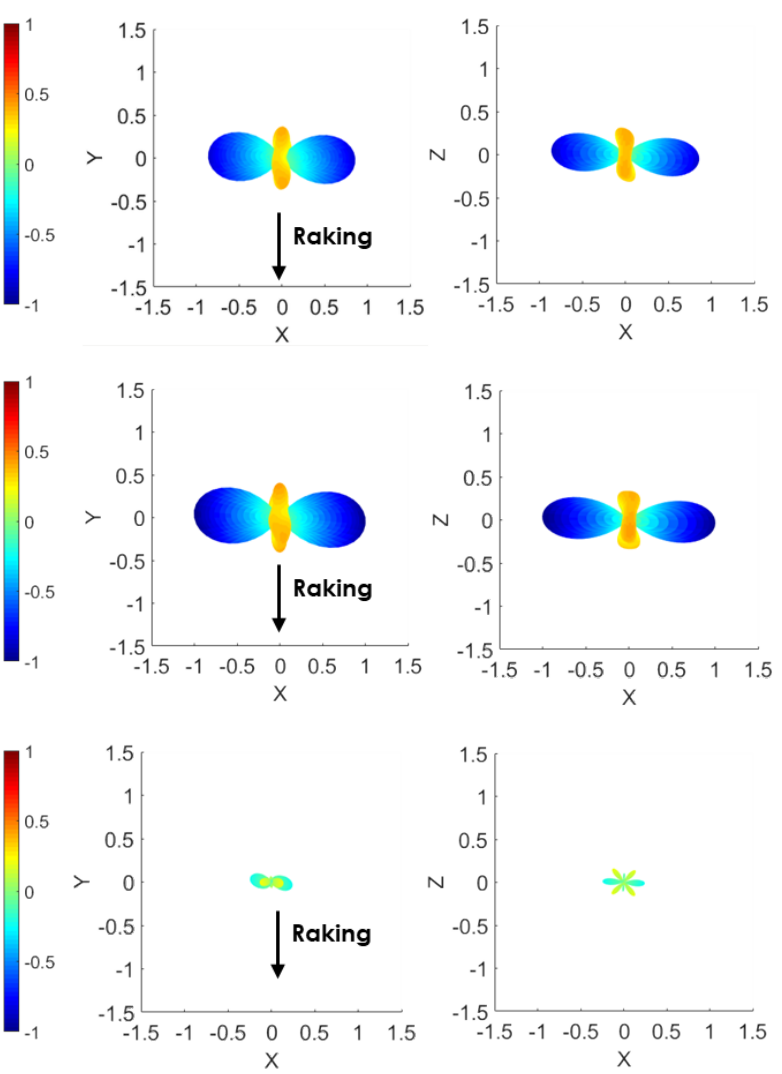

Figure 24. Evolution of fabric tensor at rake velocity $\times 5$.

Fabric tensor illustrates the directionality of the inter-particle contacts. The particle contacts are directly related to the direction of heat transfer in the powder bed. Figure 25 shows a boundary conditions of heat transfer simulation at the center region of powder bed. The heat source is assumed as hemisphere with $500 \mu \mathrm{m}$ diameter. The heat source heats the powder bed up to $1300^{\circ} \mathrm{C}$ and is immediately turned off. This mean allows us to examine heat conduction behavior through the particle contacts in the regions having different scalar and tensorial properties.

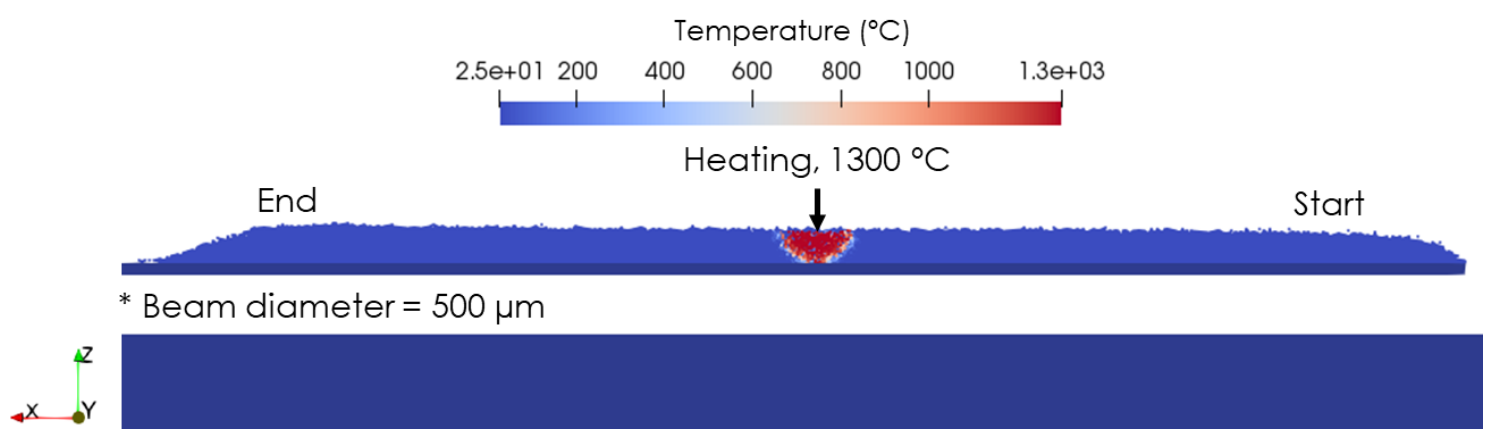

Figure 25. Initial boundary condition for heat transfer simulation. Heat source with $1300{ }^{\circ} \mathrm{C}$ and $500 \mu \mathrm{m}$ diameter was applied to heat up the powder bed. 
Figure 26 shows the temperature distribution at rake velocities of $\times 1$ that showed a stronger directionality in interparticle contacts. The same heat source was applied to the start or center or end region to check heat transfer through the particle contacts. The upper and lower temperature limit is 360 ${ }^{\circ} \mathrm{C}$ and $250{ }^{\circ} \mathrm{C}$ for Figure 26(a)-(c) to highlight the difference in the temperature distribution. It shows that the temperature distribution is skewed in Figure 26(a), so it is likely elliptical rather than the circular. It indicates that heat conduction through transverse direction (along y-axis) is stronger than longitudinal direction (along x-axis) at the start region. As the rake rearranges the interparticle contacts at the center region, the heat conducts uniformly out in all directions in Figure 26(b). Further spreading leads to additional arrangements of interparticle contacts along the raking direction. Heat transfers along the spreading direction, but the trend is subtle in Figure 26(c). The predicted peak temperatures are $342{ }^{\circ} \mathrm{C}$, $338^{\circ} \mathrm{C}$, and $348^{\circ} \mathrm{C}$ at the end of heat transfer simulation at the start, center and end region, respectively. The variation can be attributed to local variation of interparticle contacts and particle configuration within the area of heat source. Notice that the peak temperatures inversely increase with CN rather than PD in Figure 20.
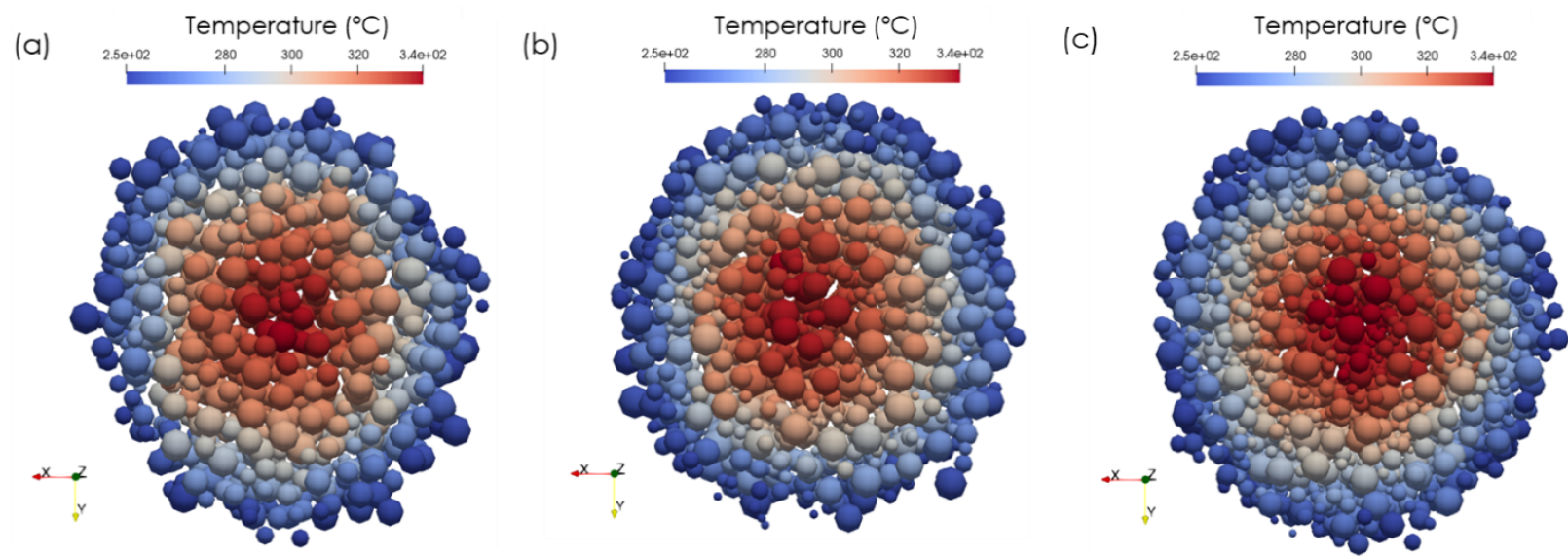

Figure 26. Temperature distribution at the end of simulation at (a) start, (b) center and (c) end region in the powder bed at $x 1$ rake velocity.

Roundness of the temperature field was examined to quantify the effect of directionality on heat conduction. The outline of the temperature field was taken from the start, center, and end region using image process software, ImageJ. The software measures the length of major axis and area of the geometry and calculates the roundness based on the equation (9). $\mathrm{R}$ is roundness, $\mathrm{A}$ is area of the shape, and $L_{\text {axis }}$ is length of major axis.

$$
R=\frac{4 \times A}{\pi \times L_{\text {axis }}}
$$

The roundness of the heat affected zones is quantified to compare the directionality of the interparticle contact related heat transfer in Figure 27. The roundness increases from the start $(=0.890)$ to center $(=0.975)$ and then it decreases from the center $(=0.975)$ to the end $(=0.954)$ region. As seen above, the shape of rose diagram was like a dumbbell at the start which shows the interparticle contacts are nonuniform whereas the shape is sphere like at the center which is uniform distribution in interparticle contacts. The same uniformity change is found in the roundness plot for heat conduction. It verifies that 
heat transfer direction follows the direction of interparticle contracts. Note that we can use this information to control heat transfer direction in the powder bed.

(a)

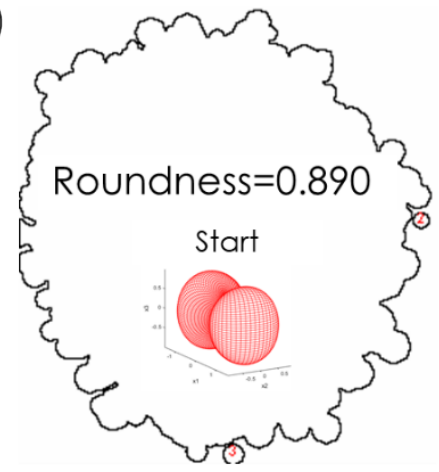

(b)

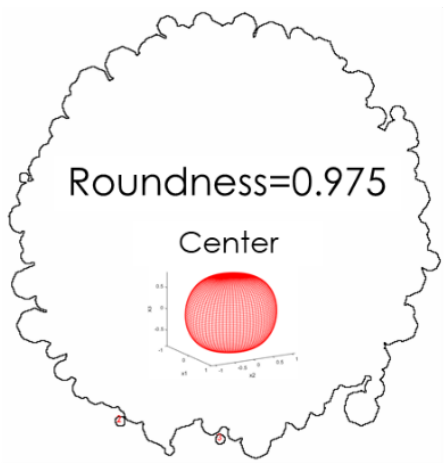

(c)

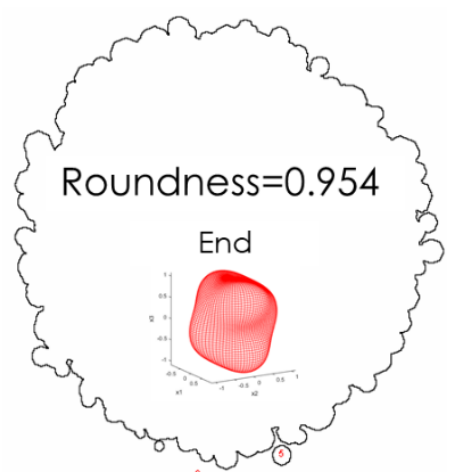

Figure 27. Roundness plot for heat conduction at the (a) start, (b) center and (b) end region in the powder bed. Smaller roundness indicates that non-uniform heat conduction occurs in the powder bed.

We show how to quantify the features of powder bed structure using the tensorial method. The next question is how to control the powder bed quality using fabric tensor. Figure 28 shows a similarity of the fabric tensors (shown in Figure 23-24) to spherical harmonic [22]. The spherical harmonics are an infinite set of harmonic functions over the sphere, which are often used in mathematics, physics, and computer science $[10,23]$. The similarity in shape leads to many useful considerations of converting the shape of the fabric tensor to the mathematical formulae of computing necessary quantities. The interparticle contact distributions can be calculated by Fourier series in 2D and spherical harmonics in 3D [10,23]. The converting provides a beneficial process parameter for manipulation of heat conditions in the powder bed, which can be controlled from the system software.

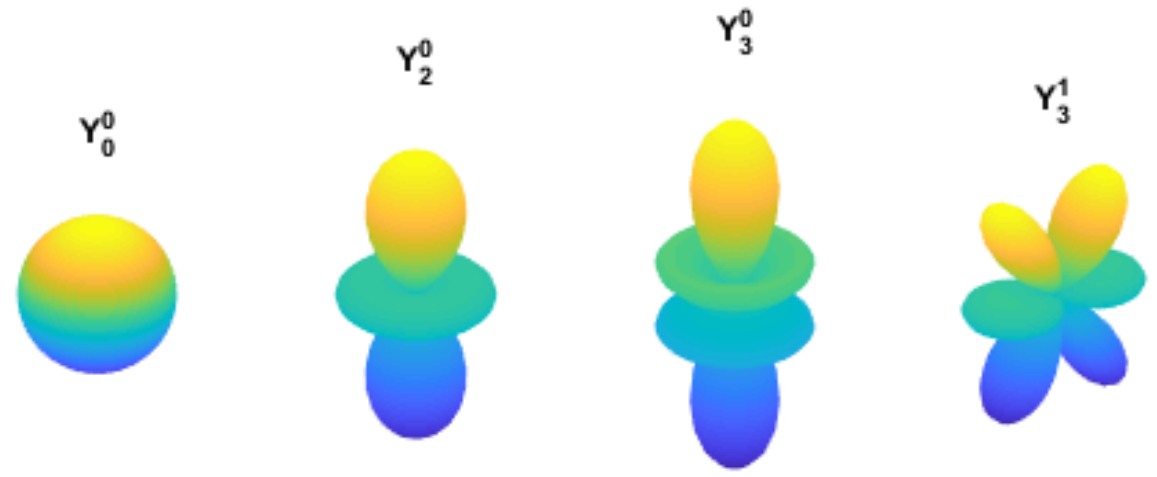

Figure 28. Representation of spherical harmonic.

\section{IMPACTS}

The developed tool fits into a broader computational modeling framework which enables end-to-end simulation of powder-bed based AM processes to support virtual process design and certification. It is estimated and reported that the AM technology can lead to small (3\% for fused deposition modeling) to extreme (98\% for laser sintering) reduction in energy consumption [24]. The established model 
potentially plays a key role in shortening the certification time for the manufacturing system and resultant reduction of the production time to market. Consequently, it reduces the cost of qualifying critical AM fabricated parts such that waste and rejected parts will be significantly reduced.

\section{PLANS FOR FUTURE COLLABORATION}

Based on the current development, the powder spreading tools can be incorporated onto additive manufacturing machines. The modeling tool potentially enables in-situ powder bed assessment to quantify powder bed structure. This computational modeling framework could be extended to different powder materials which have unlike interactive behavior to the recoater system and environment (e.g., adsorbed moisture) in packing density, particle size distribution and interparticle contacts across the powder bed for powders.

\section{SUBJECT INVENTIONS}

There are no subject inventions associated with this CRADA.

\section{COMMERCIALIZATION POSSIBILITIES}

The developed models and the simulation workflow can be organized into a software package for modeling of powder spreading in AM. The powder spreading simulations can be used as starting condition for selective melting and fusion modeling in the overall AM simulation package.

\section{CONCLUSIONS}

The project was successfully completed and met all of the targeted milestones to enable the next step in the development of powder bed AM process. The project developed a unique method for full characterization of powder bed structure using analytical and numerical modeling tools. Notable accomplishments for this project are:

- Development of DEM simulation for multi-layer powder spreading simulation. To the best of the author's knowledge, the multi-layer simulation for metal AM process has not been reported in the literature to date.

- Detailed characterization of particle's static and spreading behavior which showed a good agreement with the developed particle simulation.

- Deeper understanding of powder spreading process and particles interaction which results in a change of particle size distribution and particle segregation during the powder spreading step.

- Complete characterization of powder bed structure using scalar (porosity, surface roughness, and coordination number) and tensorial (directionality of interparticle contacts) methods which reveal that there may be an anisotropic heat transfer in the powder bed. 
- Similarity in the shape of fabric tensor with spherical harmonic may lead to beneficial consideration of converting the shape of fabric tensor to mathematical formulae which provides a beneficial process parameter controlled by the system software.

The technical scope of this work fits into a broader computational modeling framework that will enable end-to-end simulation of powder-bed based additive processes to support virtual process design and certification. Also, the project accelerates transformational technological advances in metal additive space. The developed technologies in this project support the optimization of powder spreading process, reduction of testing cycles, shortening of time to market, and reducing waste and rejected parts.

\section{REFERENCES}

1. C. Kloss, C. Goniva, A. Hager, S. Amberger and S. Pirker, Models, algorithms and validation for opensource dem and $c f d$-dem, Progress in Computational Fluid Dynamics, an International Journal 12 (2012), no. 2-3, 140-152.

2. A. Stershic, S. Simunovic and J. Nanda, Modeling the evolution of lithium-ion particle contact distributions using a fabric tensor approach, Journal of Power Sources 297 (2015), 540-550.

3. C. Meier, R. Weissbach, J. Weinberg, W. A. Wall and A. J. Hart, Modeling and characterization of cohesion in fine metal powders with a focus on additive manufacturing process simulations, Powder technology 343 (2019), 855-866.

4. C. Meier, R. Weissbach, J. Weinberg, W. A. Wall and A. J. Hart, Critical influences of particle size and adhesion on the powder layer uniformity in metal additive manufacturing, Journal of Materials Processing Technology 266 (2019), 484-501.

5. L. I. Escano, N. D. Parab, L. Xiong, Q. Guo, C. Zhao, K. Fezzaa, W. Everhart, T. Sun and L. Chen, Revealing particle-scale powder spreading dynamics in powder-bed-based additive manufacturing process by high-speed x-ray imaging, Scientific reports 8 (2018), no. 1, 15079.

6. W. Nan and M. Ghadiri, Numerical simulation of powder flow during spreading in additive manufacturing, Powder technology 342 (2019), 801-807.

7. E. Herbold, O. Walton and M. Homel, "Simulation of powder layer deposition in additive manufacturing processes using the discrete element method," Lawrence Livermore National Lab.(LLNL), Livermore, CA (United States), 2015.

8. Y. Lee and W. Zhang, Mesoscopic simulation of heat transfer and fluid flow in laser powder bed additive manufacturing, International Solid Free Form Fabrication Symposium, Austin, 2015, 1154-1165.

9. S. Plimpton, Fast parallel algorithms for short-range molecular dynamics, Journal of computational physics 117 (1995), no. 1, 1-19.

10. K. Ken-Ichi, Distribution of directional data and fabric tensors, International Journal of Engineering Science 22 (1984), no. 2, 149-164.

11. Y. Lee, P. Nandwana and W. Zhang, Dynamic simulation of powder packing structure for powder bed additive manufacturing, The International Journal of Advanced Manufacturing Technology 96 (2018), no. 1-4, 1507-1520.

12. S. Haeri, Y. Wang, O. Ghita and J. Sun, Discrete element simulation and experimental study of powder spreading process in additive manufacturing, Powder Technology 306 (2016), 45-54.

13. W. Nemec, The shape of the rose, Sedimentary Geology 59 (1988), no. 1-2, 149-152.

14. M. Mosen, Mmtensor 1.0, https://www.Mathworks.Com/matlabcentral/fileexchange/32891mmtensor-1-0, (2011). 
15. S. Haeri, Optimisation of blade type spreaders for powder bed preparation in additive manufacturing using dem simulations, Powder technology 321 (2017), 94-104.

16. H. Chen, Q. Wei, S. Wen, Z. Li and Y. Shi, Flow behavior of powder particles in layering process of selective laser melting: Numerical modeling and experimental verification based on discrete element method, International Journal of Machine Tools and Manufacture 123 (2017), 146-159.

17. H. W. Mindt, M. Megahed, N. P. Lavery, M. A. Holmes and S. G. R. Brown, Powder bed layer characteristics: The overseen first-order process input, Metallurgical and Materials Transactions A 47 (2016), no. 8, 3811-3822.

18. J. Muñiz-Lerma, A. Nommeots-Nomm, K. Waters and M. Brochu, A comprehensive approach to powder feedstock characterization for powder bed fusion additive manufacturing: A case study on alsi7mg, Materials 11 (2018), no. 12, 2386.

19. J. Zielinski, S. Vervoort, H.-W. Mindt and M. Megahed, Influence of powder bed characteristics on material quality in additive manufacturing, BHM Berg- und Hüttenmännische Monatshefte 162 (2017), no. 5, 192-198.

20. R. M. German, Coordination number changes during powder densification, Powder Technology 253 (2014), 368-376.

21. A. Gusarov, T. Laoui, L. Froyen and V. Titov, Contact thermal conductivity of a powder bed in selective laser sintering, International Journal of Heat and Mass Transfer 46 (2003), no. 6, 11031109.

22. C. Müller, Spherical harmonics, vol. 17, Springer, 2006.

23. F. Radjai, Force and fabric states in granular media, AIP Conference Proceedings, AIP, 2009, $35-42$.

24. M. Baumers, C. Tuck, R. Wildman, I. Ashcroft and R. Hague, Energy inputs to additive manufacturing: Does capacity utilization matter, Eos 1000 (2011), no. 270, 30-40. 